\title{
Human Hepatocellular Carcinoma (HCC) Cells Require Both $\alpha 3 \beta 1$ Integrin and Matrix Metalloproteinases Activity for Migration and Invasion
}

\author{
Gianluigi Giannelli, Carlo Bergamini, Emilia Fransvea, Felice Marinosci, \\ Vito Quaranta, and Salvatore Antonaci
}

Department of Internal Medicine, Immunology, and Infectious Diseases (GG, CB, EF, FM, VQ, SA), Section of Internal Medicine, University of Bari Medical School, Bari, Italy; and Department of Cell Biology (VQ), The Scripps Research Institute, La Jolla, California

\begin{abstract}
SUMMARY: Hepatocellular carcinoma (HCC) is the most frequent malignant tumor of the liver; prognosis depends on the tendency to metastasize. Cancer cell invasion is regulated by proteolytic remodeling of extracellular matrix components and by integrin expression. We have shown that matrix metalloproteinase-2 (MMP-2) and membrane-type-1 matrix metalloproteinase (MT1-MMP) cleave Laminin-5 (Ln-5), stimulating cell migration. Here we report that all HCC cells express MT1-MMP, migrate on $\mathrm{Ln}-1$ and Collagen IV, whereas only HCC cells that express $\alpha 3 \beta 1$ integrin secrete detectable levels of gelatinases, migrate on Ln-5, and invade through a reconstituted basement membrane (BM). Migration on Ln-5 is blocked by BB-94, an MMP inhibitor, and by MIG1, a monoclonal antibody that hinders migration on MMP-2-cleaved Ln-5. Invasion through a reconstituted BM is also inhibited by BB-94. HCC $\alpha 3 \beta 1$-negative cells migrate on Ln-1 and Collagen IV, but not on Ln-5, and do not invade through a reconstituted BM, although they express MT1-MMP. Anti- $\alpha 3 \beta 1$ blocking antibodies inhibit gelatinase activation, cell motility, and cell invasion through Matrigel. In vivo, $\alpha 3 \beta 1$ integrin and Ln-5 are expressed in HCC tissue but not in normal liver. In conclusion, our data suggest that both $\alpha 3 \beta 1$ integrin and gelatinase activity are required for HCC migration and invasion. (Lab Invest 2001, 81:613-627).
\end{abstract}

$H$ epatocellular carcinoma (HCC) is an epithelial cancer that originates from hepatocytes. It is the most common primary malignant tumor of the liver, and is frequently (in up to $80 \%$ of cases) associated with cirrhosis (Colombo et al, 1989). In Mediterranean countries, the incidence of HCC has constantly increased in the last ten years (Calvet et al, 1990), in line with the greater incidence of hepatitis $C$ infection (Bruix et al, 1989). Long-term prognosis of patients with $\mathrm{HCC}$ is generally poor, and survival is mainly affected by the occurrence of metastases (Yamanaka et al, 1990). Cancer metastasis is the hallmark of malignant tumors and is characterized by cells that lose their cell-cell contact, cross the basement membrane $(\mathrm{BM})$, invade the stroma, spread across blood vessels, and form new neoplastic tissue in sites other than that of the original tumor. Therefore, cell adhesion, migration, and proteolysis of extracellular matrix (ECM) proteins are regarded as important steps in the development of metastasis (Murphy and

\section{Received January 26, 2001.}

This work was supported by the Ministry for University Technological and Scientific Research (MURST) (grant to VQ) and by the Bari University Funds for Research (grant to $G G$ ).

Address reprint requests to: Dr. Gianluigi Giannelli, Dipartimento di Clinica Medica, Immunologia e Malattie Infettive, Clinica Medica II. Policlinico, Piazza G. Cesare 11, 70124, Bari, Italy. E-mail: g.giannelli@intmed.uniba.it
Gavrilovic, 1999). This seems to be particularly important in the liver, where HCC cells grow in trabecular structures that are surrounded by tissue with a high content of ECM proteins, such as laminin (Ln), Collagen (Coll), vitronectin, and fibronectin, a consequence of the development of cirrhosis (Bianchi et al, 1984). These histologic features suggest that contact between HCC cells and ECM proteins may be essential for tumor progression and metastasis. Epithelial cells, including HCC cells, adhere to and interact with ECM components through a class of transmembrane receptors, the integrins (Hynes, 1987; Ruoslahti, 1991). Integrins are a large family of transmembrane receptors that modulate cell-cell and cell-ECM contact. They are glycoproteins composed of $\alpha$ and $\beta$ subunits arranged as a long extracellular domain that mediates contact with various ECM ligands, and a relatively short intracytoplasmic tail (Ruoslahti, 1991). Integrins not only provide mechanical support for cells in contact with ECM components, but also promote a number of functions such as adhesion, migration, survival, and apoptosis in different organs and tissues, by delivering signals from the surrounding microenvironment to the cells or from inside the cells to the outside (Roskelley et al, 1995).

In tumor invasion, one of the early stages in the metastatic cascade, cancer cells detach and attach to ECM proteins in a coordinated fashion, to migrate and 
to penetrate the stroma (Kohn and Liotta, 1995). An important role must be ascribed to a family of enzymes with proteolytic activity known as matrix metalloproteinases (MMP) (Coussens and Werb, 1996). These enzymes can degrade ECM components, allowing cancer cells to spread (Kohn and Liotta, 1995). MMP-2 is secreted as a pro-enzyme with a molecular weight of $72 \mathrm{kd}$, and is activated at the cell surface by the membrane type-1 MMP (MT1-MMP) complex and the MMP-2 tissue inhibitor (TIMP-2) (Coussens and Werb, 1996; Nagase, 1997). The proteolytic activity of MMP-2 is balanced by the inhibitory effect of TIMP-2 in such a way that extensive ECM degradation can be controlled by a feedback system (Howard et al, 1991). However, an imbalance of the MMP-2 and TIMP-2 ratio has been reported in various malignancies (Coussens and Werb, 1996; Stetler-Stevenson et al, 1993). Although the mechanisms through which MMP-2 can promote cancer metastasis are not completely understood, it seems that MMP-2 is concentrated along the invasive edge of the neoplasia and degrades the ECM components of the BM, driving tumor invasion (Chen, 1992; Kohn and Liotta, 1995). In this context, MMP-2 can cleave Ln-5, one of the Ln isoforms, and convert it from a stationary to a motile substrate (Giannelli et al, 1997). Ln-5 is a heterotrimeric glycoprotein consisting of an assembly of $\alpha 3, \beta 3$, and $\gamma 2$ subunits through disulfide bonds (Burgeson et al, 1994). Ln-5 is one of the major components of the ECM and its absence causes lethal disease (Meneguzzi et al, 1992). MMP-2 and/or MT1-MMP specifically cleave the Ln-5 $\gamma 2$ chain, exposing a cryptic promigratory site that supports cell migration. The $\gamma 2$ chain of $L n-5$ seems to be involved in the metastatic process of colon and gastric cancer, and in the remodeling of the mammary gland (Giannelli et al, 1999; Koshikawa et al, 1999; Pyke et al, 1995). Epithelial cells recognize Ln-5 by the $\alpha 3 \beta 1$ and $\alpha 6 \beta 4$ integrins, which are involved in hemidesmosome formation and in static adhesion (Baker et al, 1996). However, these integrins also support epithelial cell motility in the course of several pathologic conditions (Giannelli et al, 1994; Ruoslahti and Giancotti, 1989).

Overall, these data seem to indicate that the invasive ability of cancer cells is affected by interaction between integrins and proteolytically remodeled ECM proteins. However, the studies reported in the literature have focused on single findings; a complete view of all of these features could provide useful information to help clarify the mechanisms involved in HCCcell metastasis.

The goal of this study was to investigate the invasive ability of HCC cells. For this purpose, we evaluated integrin expression, adhesive and migratory properties, and gelatinase production, activation, and inhibition in HCC cells. In this report, we distinguish between invasive and noninvasive HCC cell lines, according to whether they can invade through a reconstituted $\mathrm{BM}$ and migrate on different ECM components.

\section{Results}

HCC Cell Invasion through an In Vitro Reconstituted BM Model

To evaluate the ability of HCC cells to penetrate the surrounding tissue, we used an in vitro chemoinvasion assay. Cells plated in the upper part of the Boyden chambers came in contact with a reconstituted BM, Matrigel, mainly consisting of a mixture of Ln-1, Coll IV, and entactin assembled in a three-dimensional structure (Albini et al, 1987). In this experiment, the serum-free conditioned medium obtained from NIH3T3 cells was used as a chemoattractant and a nonconditioned serum-free medium was used as a negative control (data not shown). A well-known invasive cell line, HT1080, was used as a positive control and, as expected, was the most invasive. Invading cells were counted and three distinct experiments showing similar results reported. As reported in Figure 1, only Chang, HLE, HLF, and SK-Hep1 cells showed invasive activity, whereas Alexander, HepG2, HepG2.2.15, and Hep3B were noninvasive through the Matrigel preparation.

\section{HCC Cell Migration on Different ECM Components}

To test the hypothesis that the noninvasive HCC cells were constitutively nonmotile, we measured migratory ability on the single ECM components of the Matrigel preparation. In a haptotactic migration assay, the bottom side of polycarbonate filters were coated with Ln-1, Coll IV, or Ln-5 and the cells were plated at the top. After an appropriate incubation time, the migratory cells were counted.

As shown in Figure 2, all of the HCC cell lines, both invasive and noninvasive, were migratory on Coll IV and Ln-1. However, the invasive cell lines had better migration on Ln-5 than on Ln-1 and Coll IV. None of the HCC cell lines showed migration on blotto-coated filters used as negative controls. These results suggest that the absence of cell invasion through the Matrigel was not because of lack of migratory ability.

\section{HCC Cell Scattering on Ln-5}

To further evaluate HCC motility on Ln-5, we used a cell-scattering assay. Cells plated on tissue culture plates were incubated with Ln-5 and the morphologic changes were assessed. All of the HCC cell lines grew in island-like structures, in contact with one another (Fig. 3, a to h). However, in the presence of Ln-5, HLE (Fig. 3, a and a'), HLF (Fig. 3, b and b'), SK-Hep1 (Fig. 3, c and $c^{\prime}$ ), and Chang (Fig. 3, d and $d^{\prime}$ ) showed a scatter-like activity, whereas HepG2 (Fig. 3, e and e'), Hep3B (Fig. 3, f and f'), Alexander (Fig. 3, g and g'), and HepG2.2.15 (Fig. 3, h and h') did not. Furthermore, the island-like-structured cells were large and flat like typical stationary cells, whereas, in the presence of Ln-5, they were elongated, with filopodia and lamellipodia, like typical motile cells. These results are consistent with the migration data previously de- 


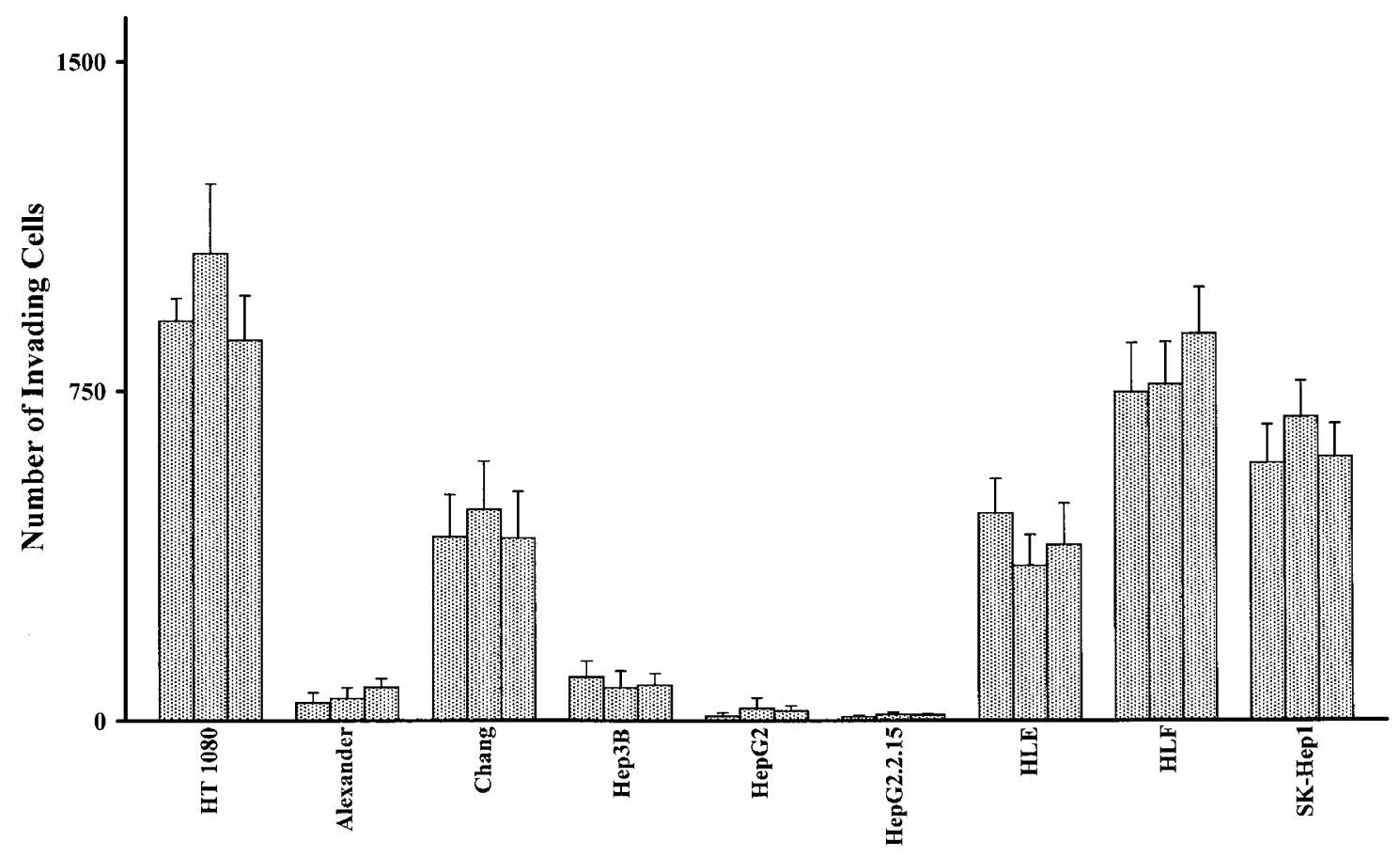

Figure 1.

Human hepatocellular carcinoma (HCC) cell invasion through a reconstituted basement membrane (BM) (Matrigel). HCC cell invasion tested with a chemoinvasion assay through Matrigel. After 6 hours, Chang, HLE, HLF, and SK-Hep1 invade through the reconstituted BM (Matrigel), whereas Alexander, Hep3B, HepG2, and HepG2.2.15 do not. HT-1080, a well-known highly invasive cell line, was used as a positive control. Invasive cells were quantified with image analysis software. Results are expressed as the mean \pm SD of the invasive cells per filter. Each condition is tested at least in quadruplicate; bars represent distinct experiments.

scribed and indicate that Ln-5 induced migration and scattering only in the invasive cell lines.

\section{Integrin Expression in HCC Cells}

To assess whether the invasive ability of HCC cells was related to the integrin phenotype, we incubated HCC cells with a number of monoclonal antibodies directed against $\alpha 2, \alpha 3, \alpha 6, \beta 1$, or $\beta 4$ integrin subunits and analyzed them with a flow cytometer. Experiments were reproduced at least three times, and each integrin subunit was studied with at least two different monoclonal antibodies. As shown in Figure 4, $\beta 1$ integrin was highly expressed on the cell surface of all of the cell lines analyzed. Similar results were obtained using two distinct monoclonal antibodies (MAR4 and TS216), both directed against the $\beta 1$ subunit. Integrins $\alpha 6$ and $\beta 4$ were recognized by the monoclonal antibodies MAR6 and GoH3, and BE12 and AA3, respectively. Immunoreactivity was observed for all HCC cell lines, although it was weak for HLE. $\alpha 2$ integrin, examined with Gi9 and P1E6, was poorly expressed on the cell surface of HLE and HLF, whereas the other cell lines displayed stronger expression. Finally, $\alpha 3$ integrin, investigated using four different monoclonal antibodies (F2, F4, F1, and P1B5), was completely absent on the cellular surface of Hep3B, HepG2, and HepG2.2.15 cells, weakly immunoreactive on Alexander, and highly expressed on the surface of the invasive cells (Fig. 4).

\section{HCC Cell Adhesion on Different ECM Components}

To quantify the adhesive properties of HCC cells and to investigate the functional role of the integrins expressed on the cell surface, we performed a rapid adhesion assay in which cells were allowed to adhere to Ln-5, Coll IV, or Ln-1. After incubation, the adhering cells were stained and solubilized, and the OD was measured with an ELISA plate reader. In line with the differences in integrin expression, the HCC cell lines adhered in different ways on ECM substrates. All of the cell lines tested show strong adhesion to Coll IV and Ln-1. Chang, HLE, HLF, and SK-Hep1 exhibited efficient adhesion to Ln-5, whereas Alexander showed poor adhesion to Ln-5, and Hep3B, HepG2, and HepG2.2.15 adhered to Ln-5 as they did to the negative control. None of the tested cell lines adhered to wells coated with blocking solution alone, used as a control (Fig. 5).

Adherent cells on Ln- 5 were plated in the presence of functional blocking anti-integrin antibodies to investigate the integrins involved in cell adhesion to $L n-5$. In a rapid adhesion assay, antibodies directed against $\alpha 3$ (P1B5) and $\beta 1$ (P4C10) integrin blocked adhesion on Ln-5 completely, whereas antibodies directed against $\alpha 2$ (P1E6) and $\alpha 6$ (GoH3) did not affect cell adhesion to Ln-5 (Fig. 6). These results suggest that $\alpha 3 \beta 1$ integrin is expressed and functionally active on the cell surface, and that it is probably involved in HCC cell adhesion to $\mathrm{Ln}-5$. 
Non Invasive Cells
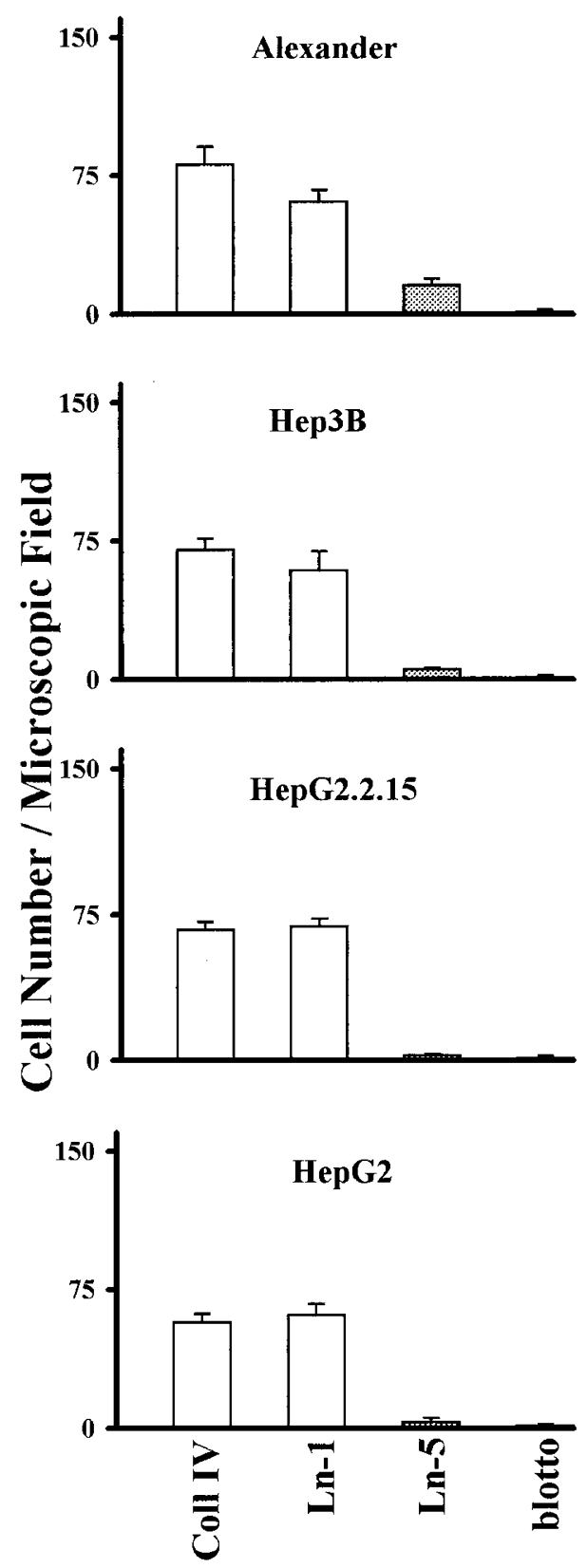

\section{Invasive Cells}
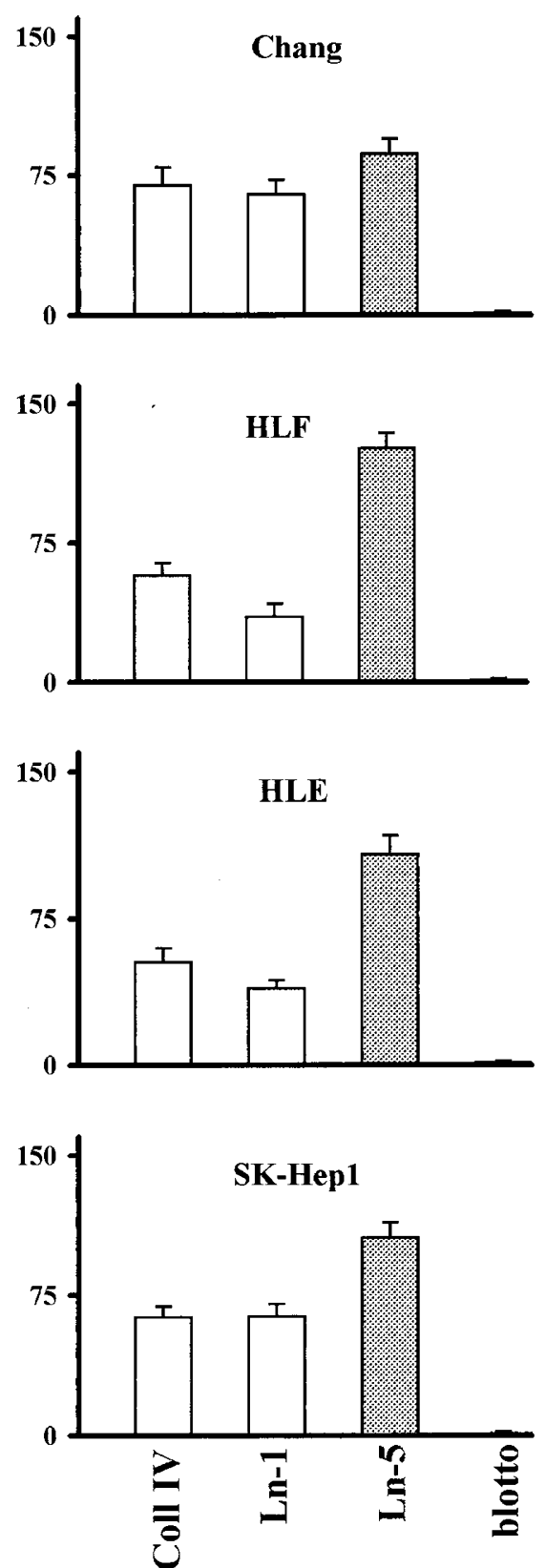

Figure 2.

HCC cell migration on extracellular matrix (ECM) proteins. All HCC cell lines migrate efficiently on transwell filters coated with Ln-1 and Coll IV (10 $\mu \mathrm{g} / \mathrm{ml})$. Chang, HLE, HLF, and SK-Hep-1 had a stronger migration on Ln-5 (1 $\mathrm{g} / \mathrm{ml}$ ) (filled bar), than on other ECM proteins; whereas Alexander, Hep3B, HepG2, and HepG2.2.15 were not motile on Ln-5. None of the HCC cell lines migrated on blotto-coated filters used as controls. Results are expressed as the mean number of cells in the microscopic field (original magnification, $\times 400) \pm$ SD.

\section{HCC Cell Expression of MMP-2, MT1-MMP, and TIMP-2}

To investigate whether the invasive ability of the HCC cells was dependent on their proteolytic activity, we evaluated MMP-2, MMP-9, MT1-MMP, and TIMP-2 expression. Conditioned media from HCC cells were concentrated and evaluated for the presence of both gelatinases, by gelatin zymography (Fig. 7A). As a positive control, we used conditioned medium of HT1080 containing MMP-2 and MMP-9 in both pro-enzyme and active form. The proenzyme forms of MMP-2 and MMP-9 have molecular weights of 72 and $92 \mathrm{kd}$, respectively, whereas their active forms have molecular weights of approximately 62 and $80 \mathrm{kd}$, respectively. A different pattern of gelatinases was observed in concentrated conditioned media from HCC cell lines (Fig. 7A). SK-Hep1 secreted MMP-9 in the conditioned medium in both inactive and active form but did not 


\section{Invasive Cells}
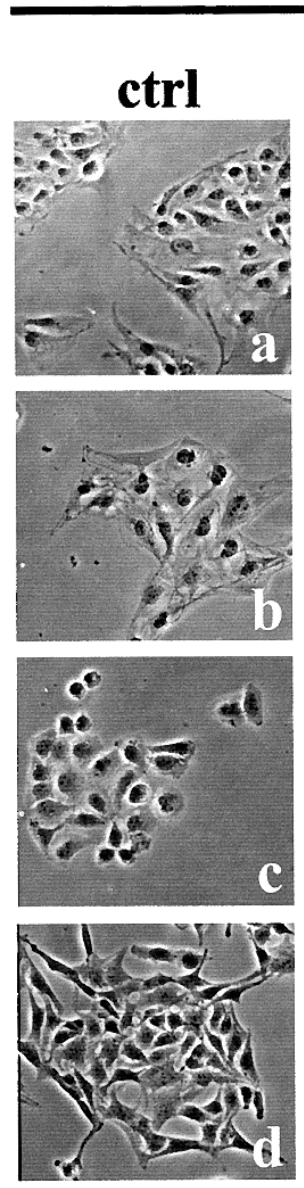
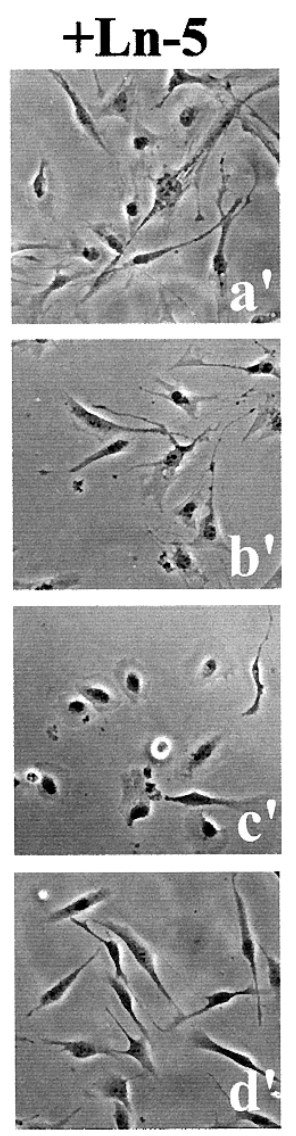

Non Invasive Cells
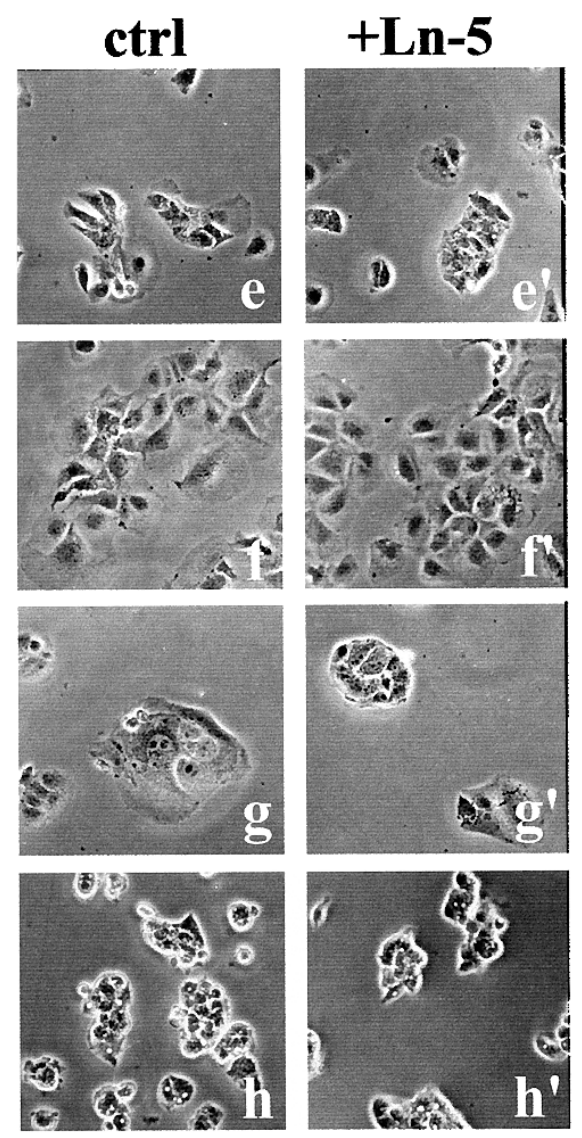

Figure 3.

HCC cell scattering on Ln-5. HCC cells seem to be in contact with one another, and are arranged as small island-like structures in control wells (a to h). In the presence of Ln-5, HLE (a and a'), HLF ( $b$ and b'), SK-Hep1 ( $c$ and $c^{\prime}$ ), and Chang ( $d$ and d') show evident scattered activity, the cells are no longer in contact, and are elongated with filopodia and lamellipodia. On the contrary, HepG2 (e and $\left.e^{\prime}\right)$, Hep3B ( $f$ and $\left.f^{\prime}\right)$, Alexander ( $g$ and $\left.g^{\prime}\right)$, and HepG2.2.15 (h and $h^{\prime}$ ) remain in contact with each other and do not scatter in the presence of $\mathrm{Ln}-5$. Cell morphologies were examined and photographed using a phase-contrast microscope (original magnification, $\times 200)$.

produce MMP-2. In contrast, Chang, HLE, and HLF cells secreted abundant MMP-2 in the conditioned medium in inactive and active forms, but did not produce MMP-9. The noninvasive cell lines failed to produce either MMP-9 or MMP-2. To confirm the data shown by the zymogram, the same concentrated conditioned media were separated by SDS-PAGE, transferred onto a polyvinylidende difluoride (PVDF) membrane, and probed with a monoclonal antibody to MMP-2. In accordance with the zymography data, MMP-2 was present in inactive and active form only in Chang, HLE, and HLF samples, and was absent in the other samples (Fig. 7B). To confirm that the lower band corresponded to active MMP-2, we analyzed conditioned media incubated with and without $\mathrm{p}$-aminophenylmercuric acetate (Giannelli et al, 1996). Although MMP-2 was present as two distinct bands in conditioned media samples, as shown in Figure 7B, in p-aminophenylmercuric acetate-incubated samples it was present as only one band, corresponding to the active MMP-2 (not shown).

Activation of MMP-2 is thought to be crucial for cancer metastasis (Coussens and Werb, 1996; Deryu- gina et al, 1998; Stetler-Stevenson et al, 1993). To investigate this, we studied the expression of TIMP-2, which cooperates with MT1-MMP in the activation of MMP-2, but also in the inhibition of proteolytic activity. Concentrated conditioned media of HCC cells were analyzed by Western blotting, and the membrane was probed with a monoclonal antibody against TIMP-2 (Fig. 7C). In this experiment, the HT1080 cell line was used as a positive control. As shown in Figure 7C, TIMP-2 was abundantly secreted in the conditioned medium of all of the HCC cell lines, no significant differences were observed among the different cell lines.

We also studied the presence of MT1-MMP in the membrane fractions of HCC cells by Western blot, using a polyclonal antibody. As shown in Figure 7D, all of the HCC cell lines studied expressed the same level of MT1-MMP in the membrane-fraction preparations. This is not surprising, because MT1-MMP is commonly expressed in epithelial cells. We also investigated the expression of gelatinases bound to the cell surfaces, because gelatinases are directly involved in 


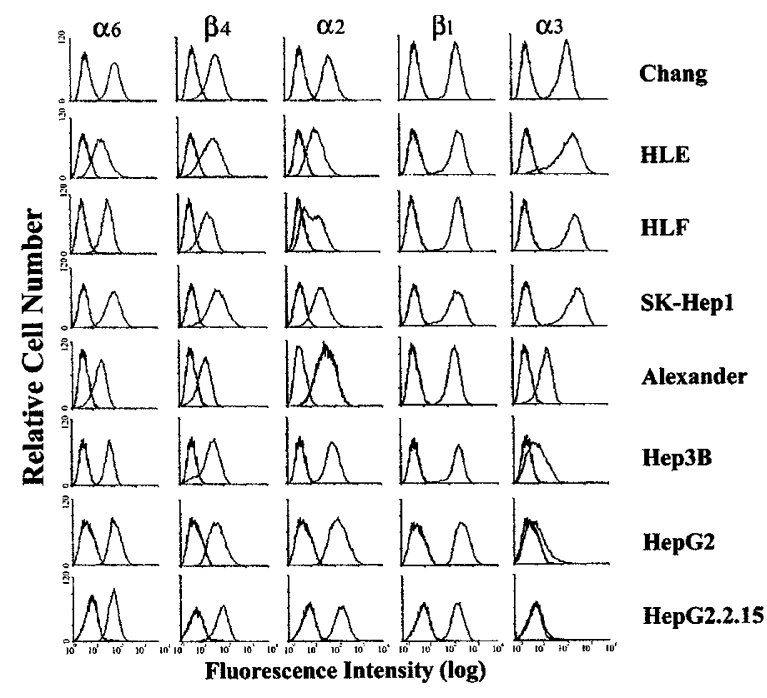

Figure 4.

Integrin expression on HCC cellular surface. All of the HCC cells studied express $\alpha 2, \beta 1, \alpha 6$, and $\beta 4$ integrin subunits. Chang, HLE, HLF, and SK-Hep1 also express high levels of the $\alpha 3$ subunit, whereas Hep3B, HepG2, and HepG2.2.15 are completely negative and Alexander show only weak immunoreactivity. As a negative control, monoclonal antibodies directed against thyroglobulin $(\mathrm{T} \gamma)$ or against $\mathrm{a}_{\mathrm{Ilb} \beta} 3$ (CP3) were used, followed by the secondary antibody. Immunohistochemistry was performed using at least two distinct monoclonal antibodies directed against each integrin subunit.

ECM proteolysis and cell motility (Murphy and Gavrilovic, 1999). In the membrane-fraction preparations, MMP-2 and MMP-9 were present in inactive and active forms only in those cells that showed gelatinolytic activity in the conditioned media, whereas no gelatinases were observed in any of the other cell lines (Fig. 7E). In conclusion, our data indicated that the invasive cell lines secreted detectable levels of MMP-2 or MMP-9 in both inactive and active forms. The noninvasive cell lines did not produce either MMP-2 or MMP-9, whereas all of the HCC cell lines produced detectable levels of MT1-MMP and TIMP-2.

\section{HCC Cells Use MMP for Invasion through Matrigel and Migration on Ln-5}

To test the hypothesis that the invasive ability of HCC cells was affected by their proteolytic capability, we performed a chemoinvasion assay in the presence of BB-94, a MMP inhibitor. As shown in Figure 8, Chang, HLE, HLF, and SK-Hep1 cell invasion through Matrigel was completely blocked by BB-94, whereas the presence of DMSO used as an inhibitor solvent had no effect. This suggests that MMP play a role in HCC invasion. Additionally, we explored the possibility that HCC cells might use the MMP-2/MT1-MMP complex to migrate on Ln-5 by adding BB-94 to the migration medium. As shown in Figure 9, BB-94 blocked migration on Ln-5 in a dose-dependent manner, whereas, in the presence of dimethyl sulfoxide (DMSO) alone, cells migrated as efficiently as in control filters. To investigate whether Ln-5 was supporting migration because of $\gamma 2$ chain cleavage, we added MIG1 antibody to the migration medium, because we have shown that it blocks acquired migration on cleaved Ln-5 (Giannelli
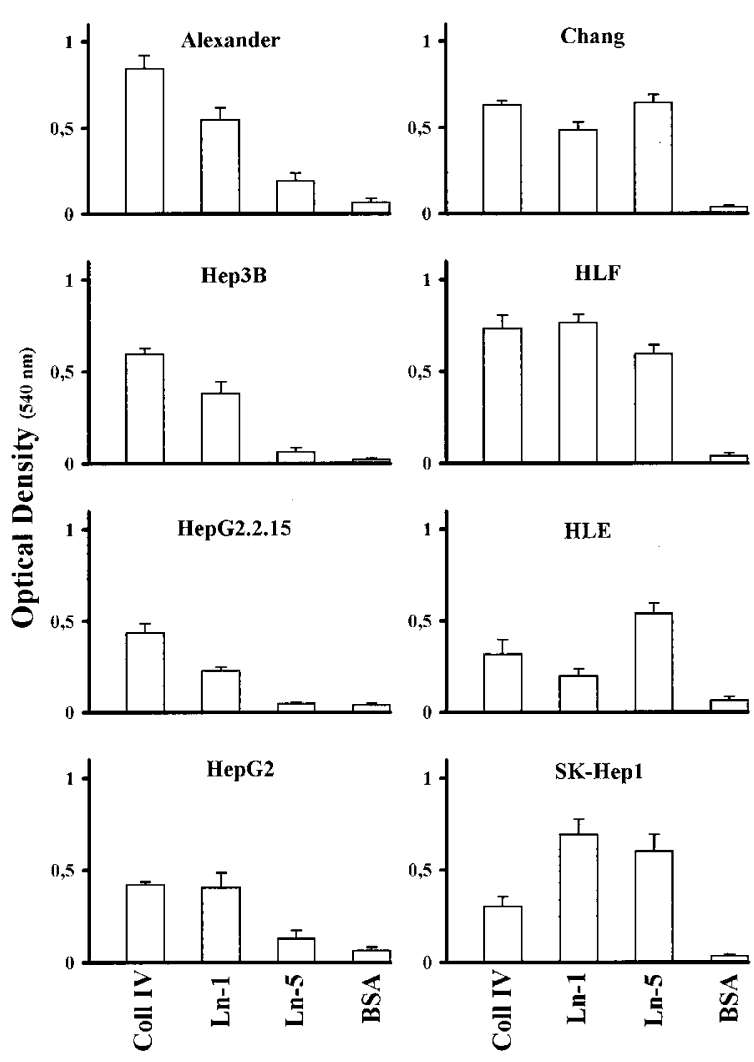

Figure 5

HCC cell adhesion on ECM proteins. HCC cells adhere strongly on Ln-1 and Coll IV $(10 \mu \mathrm{g} / \mathrm{ml})$, with some differences between each cell line. Chang, HLE, HLF, and SK-Hep1 adhere strongly on Ln-5 $(1 \mu \mathrm{g} / \mathrm{ml})$, whereas Hep3B, HepG2, and HepG2.2.15 do not. Alexander shows only weak adhesion. Wells coated with $10 \%$ BSA in PBS were used as a negative control. Experiments are quantified as the mean of three different wells $\pm \mathrm{SD}$, where adherent cells were stained and solubilized, and OD was measured with an ELISA plate reader.

et al, 1997). As controls, we used CM6 and TR1, ie, a functional and a nonfunctional antibody to Ln-5. As expected, CM6 blocked migration but TR1 did not (Fig. 10). Under the same conditions, the MIG1 antibody strongly inhibited migration compared with controls. Furthermore, the addition of exogenous MMP-2 to the migration medium of the noninvasive cells did not increase their motility on Ln-5, whereas it increased the motility of MCF-10 used as a control (not shown); as we described previously (Giannelli et al, 1997). Therefore, the migratory ability of invasive cells on Ln-5 was blocked by BB-94 and MIG1, suggesting a crucial role for MMP activity.

The above results are summarized in Table 1 . The invasive HCC cells expressed high levels of $\alpha 3$ integrin, migrated efficiently on Ln-5, and secreted significant levels of MMP-2 or MMP-9. On the contrary, their noninvasive counterparts expressed low or undetectable levels of $\alpha 3$ integrin, did not migrate on Ln-5, and did not secrete either MMP-2 or MMP-9. Finally, all of the HCC cell lines expressed MT1-MMP and TIMP-2. These results suggest that both integrin $\alpha 3 \beta 1$ and MMP activity have a role in cell migration and invasion. 

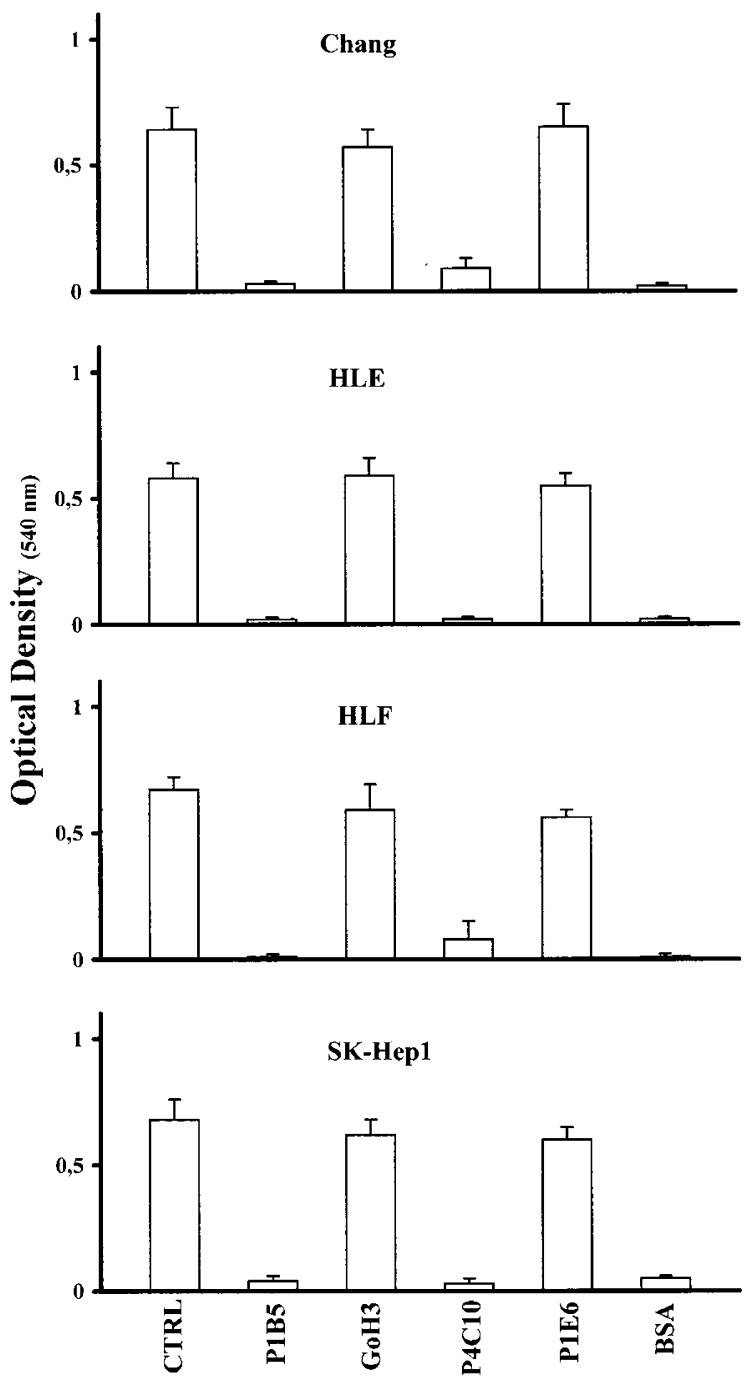

Figure 6.

HCC cells adhere on Ln- 5 via $\alpha 3 \beta 1$ integrin. Chang, HLE, HLF, and SK-Hep1 were plated on Ln- 5 coated wells in the presence of anti-integrin functional antibodies. After incubation, adhesion on Ln-5 is inhibited by blocking antibodies directed against $\alpha 3$ (P1B5) and $\beta 1$ (P4C10), but not by blocking antibodies directed against $\alpha 2$ (P1E6) and $\alpha 6(\mathrm{GoH} 3)$. No antibodies were added in control (CTRL) wells. Cell adhesion was quantified as described in Figure 5 .

\section{HCC Cell Invasion Is Regulated by $\alpha 3 \beta 1$ Integrin}

To investigate the role of $\alpha 3$ integrin in regulating HCC cell motility and invasion, we added functional antibodies to integrin during cell scattering and chemoinvasion assays. As shown in Figure 11, anti- $\alpha 3$ and anti- $\beta 1$ integrin functional antibodies blocked the HLE scattering induced by $\mathrm{Ln}-5$, whereas in the presence of anti- $\alpha 2$ and anti- $\alpha 6$ integrin functional antibodies, the cells scattered similar to controls. Similar results were obtained with the other invasive cell lines (not shown). This suggests that motility on Ln- 5 is mediated by $\alpha 3 \beta 1$ integrin. To assess the role of this integrin in the invasion process, anti-integrin functional antibodies were added during the chemoinvasion assay. As reported in Figure 11, HLE invasion was inhibited by anti- $\alpha 3$ and anti- $\beta 1$ functional antibodies,
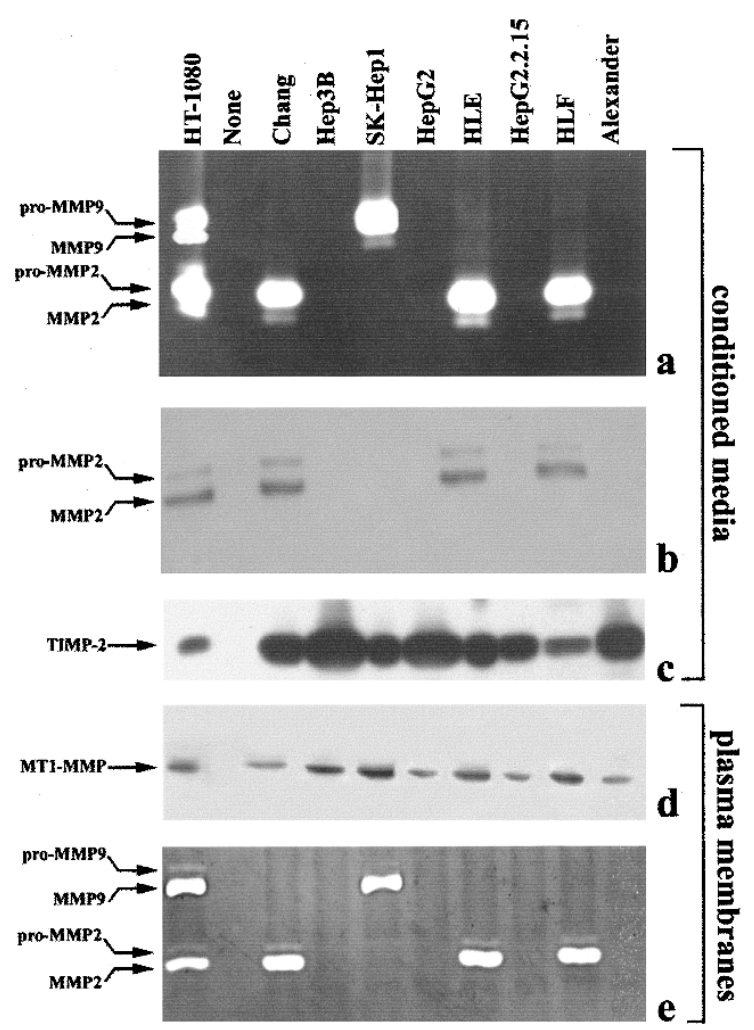

Figure 7.

HCC cell expression of MMP-2, MMP-9, MT1-MMP, and TIMP-2. Chang, HLE, and HLF secrete detectable levels of inactive and active MMP-2, but not of MMP-9 in serum-free medium. On the contrary, Sk-Hep1 secretes MMP-9 but not MMP-2, whereas Hep3B, Alexander, HepG2, and HepG2.2.15 do not secrete MMP-2 or MMP-9, as shown in Panel a. To confirm the presence of MMP-2 in HCC concentrated media, samples were analyzed by Western blotting and the membrane was probed with a monoclonal antibody against MMP-2, as reported in Panel b. In conditioned media preparations, the expression of TIMP-2 was also investigated by Western blot using a monoclonal antibody. As seen in Panel c, TIMP-2 is present in all HCC cell lines. MT1-MMP was investigated in plasma membrane by western blot using a polyclonal antibody. As shown in Panel d, MT1-MMP was expressed on the cell surface of all of the HCC cell lines. Plasma membranes were also evaluated for MMP expression because ECM proteolysis occurs at the cellular advancing edge, in a focused manner. Consistent with the data found in the zymogram, in Panel e, MMP-2 is present in Chang, HLE, and HLF preparations, MMP-9 is present only in SK-Hep1, and no MMP are detectable in the Hep3B, HepG2, HepG2.2.15, or Alexander samples.

whereas anti- $\alpha 2$ and anti- $\alpha 6$ did not affect cell invasion. HLE-conditioned media collected in the presence of anti- $\alpha 3$ and anti- $\alpha 6$ functional antibody were concentrated and analyzed by gelatin zymography. MMP-2 was present only in latent form in the HLEconditioned medium treated with anti- $\alpha 3$ functional antibodies, whereas it was present in both latent and active forms in anti- $\alpha 6$ treated-conditioned medium, as in controls. Similar results were obtained with other HCC invasive cells, with the exception of SK-Hep1, in which MMP-9 activation was inhibited (not shown). These results suggest that $\alpha 3$ integrin is involved in HCC cell invasion, modulating gelatinase activation.

\section{$\alpha 3 \beta 1$ Integrin and Ln-5 Expression in HCC Tissue}

We investigated the roles of integrin $\alpha 3$ and Ln-5 in vivo using immunohistochemistry. We processed se- 

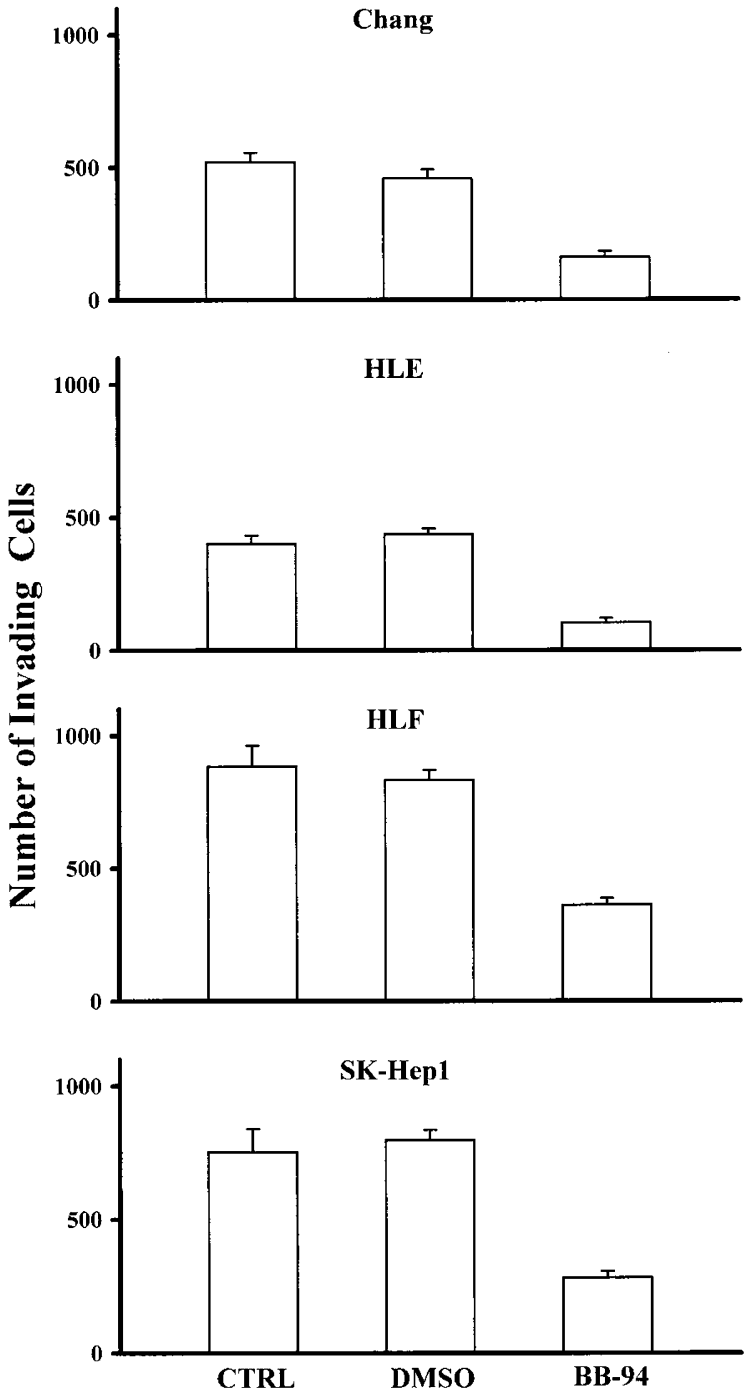

Figure 8.

BB-94 inhibits HCC cell invasion through a reconstituted BM. Chang, HLE, HLF, and SK-Hep1 invasive activity was tested in the presence of BB-94 or in DMSO. Sixty percent of the invasion is inhibited by BB-94 but not by DMSO alone, where the invasion is similar to nontreated filters (CTRL).

rial sections of HCC tissue and liver from healthy subjects undergoing surgery for other reasons. As shown in Figure 12, in a normal liver, $\alpha 3$ integrin was present in the blood vessel endothelial cells in the portal spaces, but was absent from the parenchyma. In HCC tissues, $\alpha 3$ integrin was highly expressed by cancer cells, with a diffuse pattern in the parenchyma. This result was confirmed by using five different monoclonal antibodies directed against $\alpha 3$ integrin. In normal liver, Ln-5, immunolocalized by the GB3 monoclonal antibody, was detected in the BM of the vessels in the portal spaces, but was absent from the parenchyma. In HCC sections, Ln-5 was irregularly expressed in patches in the parenchyma. These observations were consistent in all tissues examined. The expression of both $\alpha 3$ integrin and Ln-5 in HCC tissues but not in normal liver suggests their involvement in the spread of the tumor.
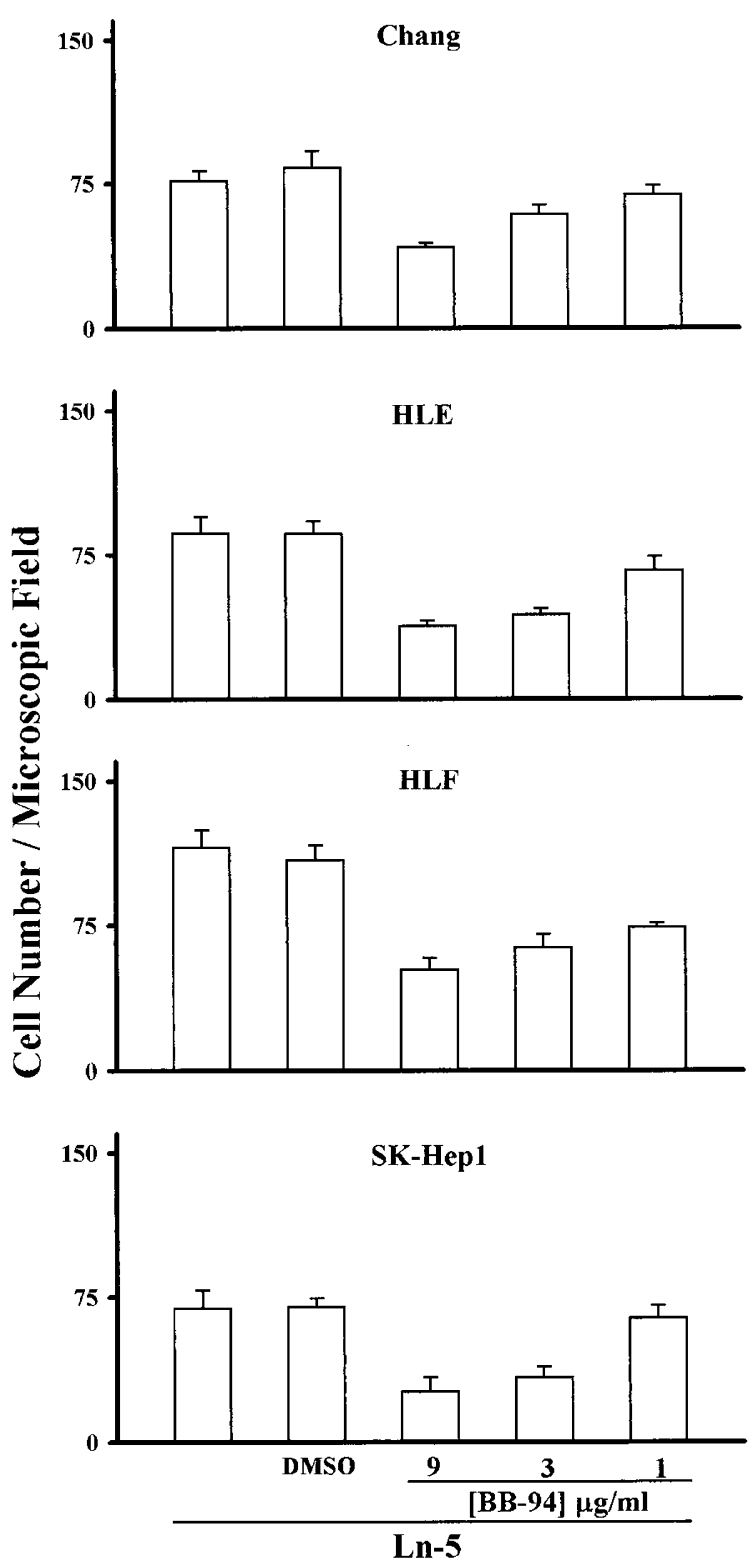

Figure 9.

BB-94 inhibits HCC cell migration on Ln-5. Chang, HLE, HLF, and SK-Hep1 migration was examined in the presence of BB-94 (from 3 to $9 \mu \mathrm{g} / \mathrm{ml}$ ), or at the highest concentration of DMSO used to dilute the MMP inhibitor. BB-94 inhibits HCC migration on Ln-5 in a dose-dependent manner, whereas cells migrate efficiently in the presence of DMSO, similar to the nontreated wells used as a control.

\section{Discussion}

We studied the migratory and invasive ability of HCC cells. We found that both $\alpha 3 \beta 1$ integrin and MMP proteolytic activity were required for HCC cells to migrate on Ln-5 and to invade through a reconstituted BM. This conclusion was based on the following observations: (a) only HCC cells that were strongly immunoreactive for $\alpha 3 \beta 1$ migrated efficiently on Ln-5, (b) migration on Ln-5 was abolished by the MMP inhibitor BB-94 and by the MIG1 monoclonal antibody, which blocked motility on MMP-cleaved Ln-5; (c) invasion through a reconstituted BM was blocked by 

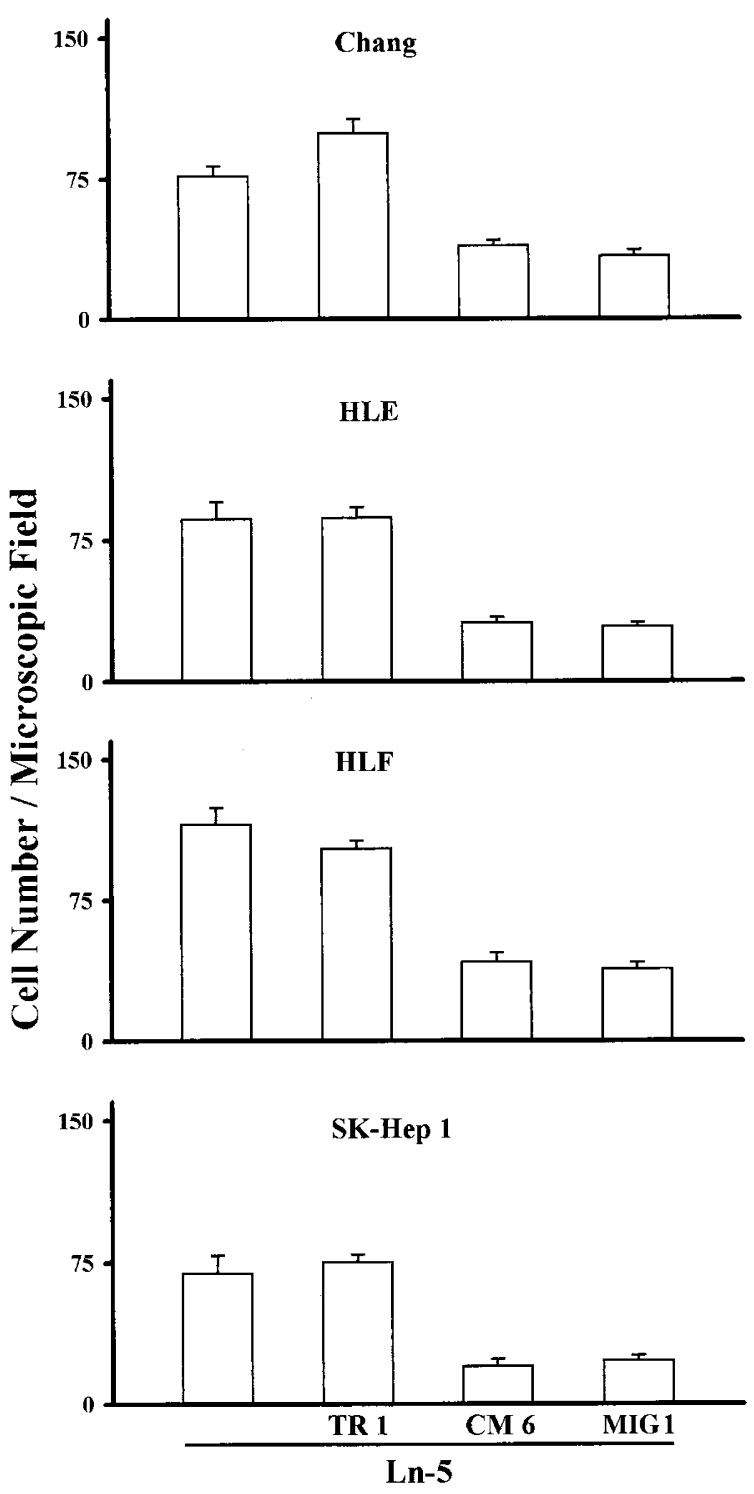

Figure 10.

MIG1 inhibits HCC cell migration on Ln-5. Chang, HLE, HLF, and SK-Hep1 migration was examined in the presence of MIG1, TR1, and CM6 $(30 \mu \mathrm{g} / \mathrm{ml})$ monoclonal antibodies against $L n-5$, under the same conditions as those described in "Materials and Methods". Cell migration is blocked by MIG1. TR1 and CM6 monoclonal antibodies were used as a control.

BB-94; (d) anti- $\alpha 3$ and $\beta 1$ blocking antibodies inhibited scattering, invasion through a reconstituted BM, and gelatinase activation; (e) in vivo, $\alpha 3$ integrin and Ln-5 were highly expressed in HCC tissues but not in normal liver.

That migration of HCC cells should occur on cleaved Ln-5 is consistent with our previous results, where we reported that MMP-2 and/or MT1-MMP cleave the Ln-5 $\gamma 2$ chain, stimulating breast and colon cancer cell migration (Giannelli et al, 1997; Koshikawa et al, 2000). However, noninvasive HCC cells express MT1-MMP but do not migrate on Ln-5, even in the presence of added exogenous MMP-2. These contradictory results might be explained by the fact that nonmigratory cells hardly express $\alpha 3 \beta 1$ integrin, which is also absent in normal adult hepa- tocytes; whereas it is highly expressed in hepatocytes that are migrating from the endoderm germ layer to the mesenchyme of the septum transversum during embryogenesis (Lora et al, 1998; Nejjari et al, 1999; Scoazec et al, 1996). We found that $\alpha 3 \beta 1$ was expressed in HCC tissue, suggesting a role for this integrin in migration on ECM components such as Ln-5 and in metastasis formations. In contrast, integrin $\alpha 6 \beta 1$ was suggested to have a central role in HCC cell motility and invasion, in another study. However, different experimental conditions and reagents were used, therefore other mechanisms could be implicated (Kleinman et al, 1982; Nejjari et al, 1999). In our study, tumor cell invasion through a BM Matrigel preparation seemed to be caused predominantly by integrin $\alpha 3 \beta 1$ but not $\alpha 6 \beta 1$ because (a) the noninvasive HCC cells expressed similar or higher levels of $\alpha 6 \beta 1$ than the invasive cells, and (b) anti- $\alpha 3$ but not anti- $\alpha 6$ integrin functional antibodies inhibited cell invasion and gelatinase activation. A role for $\alpha 3 \beta 1$ integrin in modulating proteolytic activity has been proposed, although this is somewhat controversial. In rhabdomyosarcoma and glioblastoma tumors, anti- $\alpha 3 \beta 1$ blocking antibody stimulates cell invasion and MMP-2 secretion, whereas in breast cancer it inhibits cell invasion and MMP-9 secretion (Chintala et al, 1996; Kubota et al, 1997; Morini et al, 2000). Furthermore, in melanoma cells the same antibody also inhibits cell migration and invasion, and in immortalized keratinocytes a deficiency of $\alpha 3 \beta 1$ integrin suppresses MMP-9 expression. (DiPersio et al, 2000; Melchiori et al, 1995). The novelty here is that $\alpha 3 \beta 1$ integrin was involved in MMP-2 activation. Thus, it seems likely that $\alpha 3 \beta 1$ could have different functions in different organs, such as reported for $\alpha 6 \beta 4$, which provides static adhesion of keratinocytes but promotes breast cancer migration and invasion (Shaw et al, 1997). Alternatively, $\alpha 3 \beta 1$ could modulate cell functions without being directly engaged with ECM components, as recently proposed (Kreidberg, 2000). This could be the case with HCC $\alpha 3 \beta 1$-negative cells that do not invade through Matrigel, although they express MT1-MMP and migrate efficiently on Ln-1 and Coll IV, which are the main components of the Matrigel preparation (Kleinman et al, 1982). In HCC $\alpha 3 \beta 1$-negative cells, a lack of $\alpha 3 \beta 1$ could reflect a failure in the activation of phosphoinositide 3-kinase dependent pathways involved in cell invasion (Sugiura and Berditchevski, 1999). Alternatively, this discrepancy could be because MT1-MMP, in the absence of MMP-2 or MMP-9, was not sufficient to allow cell invasion through a three-dimensional structure such as Matrigel. Recently, a role for Ln-5 in stimulating malignant glioma cell invasion through Matrigel was reported (Fukushima et al, 1998). We found that Ln-5 was present in HCC tissues that were directly in contact with the cells, where it could be used as a migratory substrate for invading cells that express $\alpha 3 \beta 1$ integrin; whereas we confirmed that Ln- 5 was absent in normal liver, as previously reported (Mi- 
Table 1. Summary of the "Invasive" and "Noninvasive" HCC Cell Features

\begin{tabular}{|c|c|c|c|c|c|c|c|}
\hline Cell type & & $\begin{array}{l}\text { Matrigel } \\
\text { invasion }\end{array}$ & $\begin{array}{c}\alpha 3 \\
\text { expression }\end{array}$ & $\begin{array}{c}\mathrm{Ln}-5 \\
\text { migration }\end{array}$ & MMP-2/9 & MT1-MMP & TIMP-2 \\
\hline \multirow[t]{4}{*}{ Invasive cells } & Chang & ++ & +++ & ++ & $+/-$ & + & + \\
\hline & HLE & ++ & +++ & +++ & $+1-$ & + & + \\
\hline & HLF & +++ & +++ & +++ & $+/-$ & + & + \\
\hline & SK-Hep1 & +++ & +++ & +++ & $-1+$ & + & + \\
\hline \multirow[t]{4}{*}{ Noninvasive cells } & Alexander & - & \pm & \pm & $-1-$ & + & + \\
\hline & Нер3В & - & - & - & $-1-$ & + & + \\
\hline & HepG2 & - & - & - & $-1-$ & + & + \\
\hline & HepG2.2.15 & - & - & - & $-1-$ & + & + \\
\hline
\end{tabular}

Ln-5, laminin-5; MMP-2/9, matrix metalloproteinase 2/9; MT1-MMP, membrane-type 1 matrix metalloproteinase; TIMP-2, MMP-2 tissue inhibitor; +, expression; - , lack of expression.

a
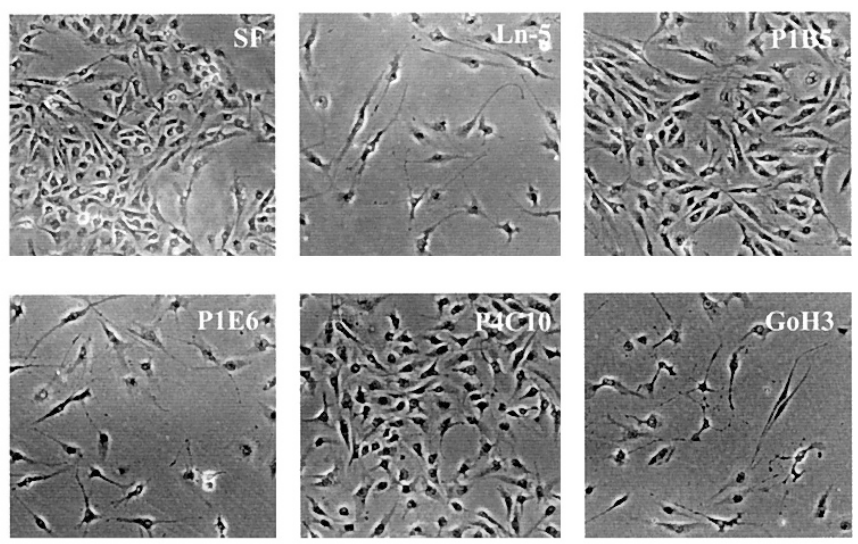

b

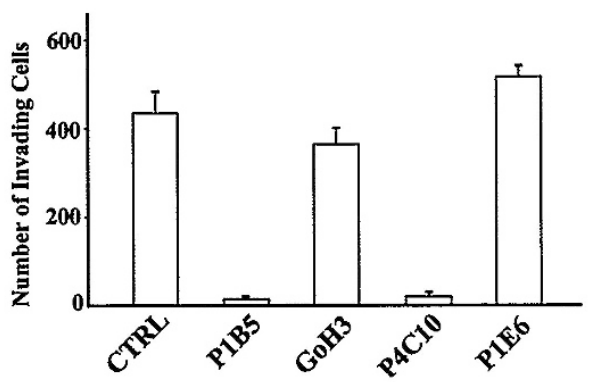

c

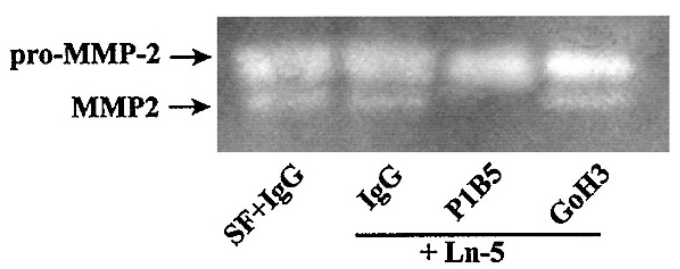

\section{Figure 11.}

Integrin $\alpha 3 \beta 1$ regulates MMP-2 activation and HCC invasion. The HLE scattering assay was performed in the presence of Ln- 5 and anti-integrin functional monoclonal antibodies $(30 \mu \mathrm{g} / \mathrm{ml})$. The Ln-5 scattering effect was blocked by P1B5 (anti- $\alpha 3$ ) and by P4C10 (anti- $\beta 1$ ) antibodies, whereas, in the presence of P1E6 (anti- $\alpha 2$ ) or GoH3 (anti- $\alpha 6$ ), cells scatter similar to the Ln-5 control. HLE growth in serum-free conditions was used as a control (SF) (original magnification, $\times 100)$ (Panel a) The same antibodies also inhibited HLE cell invasion through a reconstituted BM (Panel b). Conditioned media from cell scattering experiments were analyzed by zymography. P1B5 inhibits MMP-2 activation but GoH3 does not (Panel c).

zushima et al, 1996). The role of Ln-5 in the liver is not yet clear but it induces motility and scattering of rat liver hepatocytes (Miyazaki et al, 1993b). In other cancer tissues, the $\gamma 2$ chain of $L n-5$ is expressed at the advancing edge of cancer cells and colocalized with the receptor for urokinase plasminogen activator, implying a role in the spread of cancer cells (Pyke et al, 1995). More recently, the $\gamma 2$ but not the 

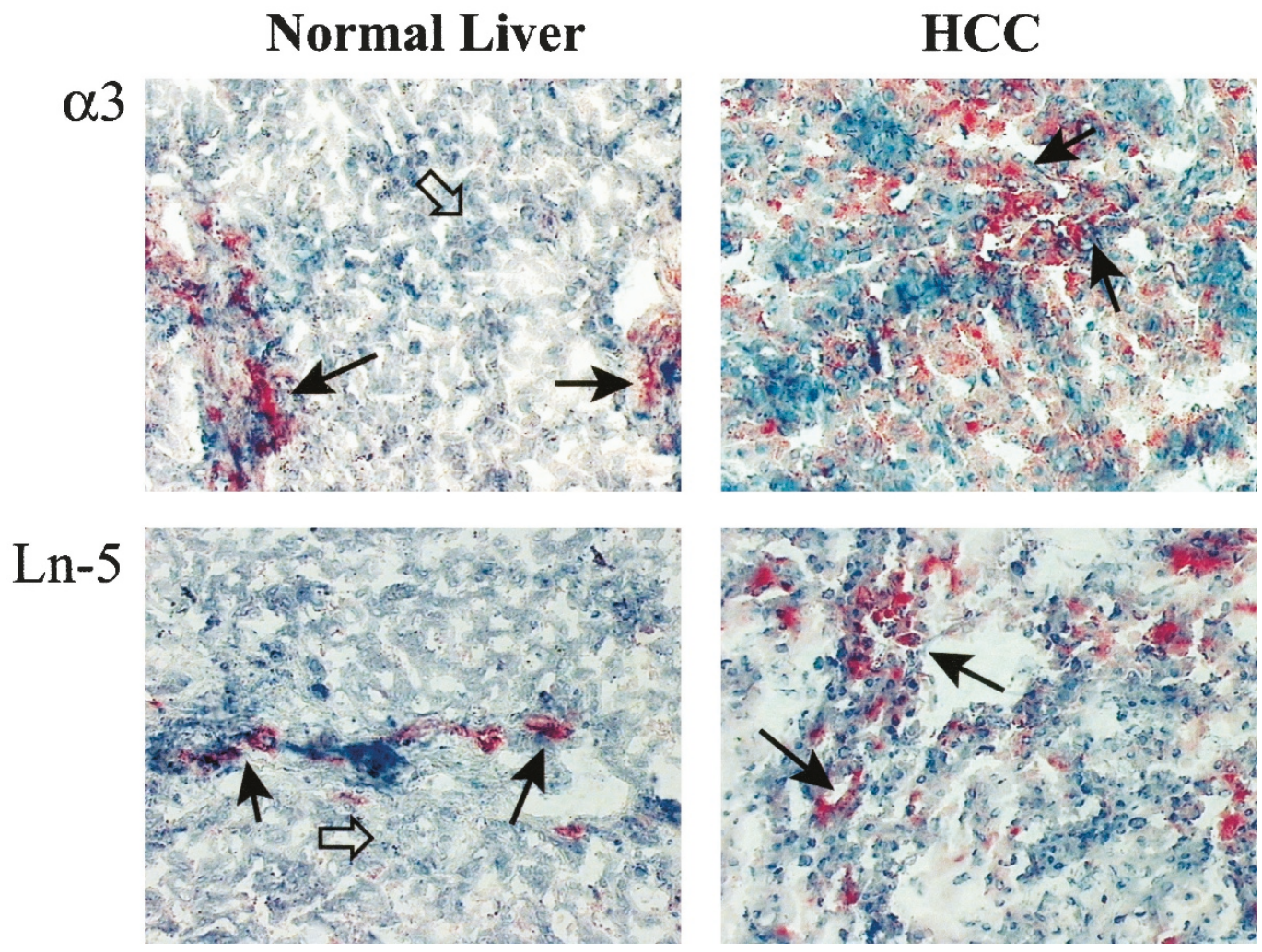

\section{Figure 12.}

In vivo, $\alpha 3 \beta 1$ integrin and Ln-5 are expressed in HCC but not in normal tissue. Frozen sections of normal liver and HCC tissue were processed for indirect alkaline phosphatase immunohistochemistry. In normal tissue, $\alpha 3$ integrin and Ln-5 were present in blood vessels in portal spaces (filled arrows), but were absent in the parenchyma (empty arrows). In HCC tissues, $\alpha 3$ integrin and Ln-5 were also expressed by liver cancer cells in the parenchyma (black arrows) (original magnification, $\times 200)$.

$\alpha 3$ or $\beta 3$ chains of Ln-5 were found in invading gastric carcinoma cells and could be involved in cell invasion (Koshikawa et al, 1999). In conclusion, this is the first study to detect $\alpha 3$ integrin and Ln-5 in HCC tissues, and to evaluate integrin expression, MMP proteolytic activity, migration, and invasion ability in the same scenario. Based on our results, we suggest that HCC cells could use $\alpha 3 \beta 1$ integrin to migrate on Ln-5 cleaved by MT1-MMP and/or MMP-2, which may stimulate cell migration and invasion. In such a system, $\alpha 3 \beta 1$ integrin could play a central role in gelatinase activation and, therefore, favor migration and invasion.

\section{Materials and Methods}

\section{Cell Culture}

The human HCC cell lines Hep3B, Alexander, HepG2, and SK-Hep1; the fibrosarcoma cell line HT1080; the murine fibroblast cell line NIH3T3; the human hepatoma liver cell line Chang; and the human mammary epithelial cell line MCF-10 were obtained from the American Type Tissue Culture Collection (ATCC, Rockville, Maryland). Other HCC cell lines, ie, HLE and HLF, were obtained from the Japanese Cancer Resources Bank (JCRB, Tokyo, Japan). HepG2.2.15, a human hepatoma cell line transfected with the human hepatitis B virus (Raney et al, 1990), was kindly pro- vided by A. McLachalan (The Scripps Research Institute, La Jolla, California). Chang, Hep3B, SK-Hep1, $\mathrm{NIH} 3 \mathrm{~T} 3$, and HT1080 cells were maintained in DMEM (Gibco, Grand Island, New York) supplemented with $10 \%$ (v/v) FCS (Mascia Brunelli, Milan, Italy), $2 \mathrm{~mm} / \mathrm{L}$ of L-glutamine, $20 \mathrm{U} / \mathrm{ml}$ of penicillin, and $20 \mathrm{mg} / \mathrm{ml}$ of streptomycin (Gibco). HLE, HLF, HepG2, HepG2.2.15, and Alexander were maintained in RPMI (Gibco), supplemented with $10 \%(\mathrm{v} / \mathrm{v}) \mathrm{FCS}$, L-glutamine, penicillin, and streptomycin. MCF-10 cells were maintained in a DFCl-enriched medium as described (Band and Sager, 1989). All cells were maintained at $37^{\circ} \mathrm{C}$ in a humidified incubator containing $5 \% \mathrm{CO}_{2}$.

\section{Reagents}

Monoclonal antibodies MIG1, TR1, and CM6 (against rat Ln-5), BE12 and AA3 (against human $\beta 4$ ) were prepared as described (Kajiji et al, 1989; Plopper et al, 1996). A monoclonal antibody against human TIMP-2 was kindly provided by K. Miyazaki (Division of Cell Biology, Institute for Biological Research, Yokohama, Japan) (Miyazaki et al, 1993a). A polyclonal antibody against human MT1-MMP was purchased from Chemicon International Ltd. (Temecula, California). A monoclonal antibody against human MMP-2 was purchased from Oncogene (Cambridge, Massachusetts). Gi9, a monoclonal antibody to human $\alpha 2$ was pur- 
chased from Immunotech (Marseilles, France). Antibodies F2, F4, and F1 (against human $\alpha 3$ ) (Bartolazzi et al, 1993) were kindly provided by L. Zardi (Istituto Scientifico Tumori, Genoa, Italy). MAR6 and MAR4 antibodies (to human $\alpha 6$ and $\beta 1$, respectively) (Bottini et al, 1993; Pellegrini et al, 1992) were a gift from S. Menard (Istituto Nazionale Tumori, Milan, Italy). Function-blocking antibodies against human $\alpha 2, \alpha 3$, and $\beta 1$ integrin (P1E6, P1B5, and P4C10, respectively) were purchased from Gibco (Gaithersburg, Maryland). $\alpha 6$ (GoH3) was purchased from Pharmingen (San Diego, California). The monoclonal antibodies directed to thyroglobulin (T $\gamma$ ) or against $\alpha_{1 \mathrm{lb} \beta} 3$ (CP3) were a gift of Z. Ruggeri (The Scripps Research Institute, La Jolla, California). The BB-94 MMP inhibitor was kindly provided by British Biotech Technology Ltd., (Oxford, United Kingdom) and diluted in DMSO, following the manufacturer's instructions. Rat Ln-5 was purified as previously described (Koshikawa et al, 2000). Ln-1 and Coll IV were purchased from Sigma Chemical Company (St. Louis, Missouri). The monoclonal antibody to human Ln-5 (GB3) (Vailly et al, 1994) was a gift of G. Meneguzzi (School of Medicine, Nice, France). The fluorescein isothiocyanate-labeled goat antimouse secondary antibody was purchased from Zymed (San Francisco, California). A reduced growth factor Matrigel matrix was purchased from Becton Dickinson (Bedford, Massachusetts). The conditioned serum-free medium of NIH3T3 cells was collected after 24 hours, aliquoted, and frozen. A new aliquot was used for each experiment. Human recombinant MMP-2 (Fridman et al, 1993) was kindly supplied by W.G. Stetler-Stevenson (Bethesda, Maryland).

\section{FACS Analysis}

Cells were trypsinized and gently washed with icecold Tris PBS (TBS) pH 7.4 containing $2 \%$ FCS, and centrifuged at low speed $(400 \times g)$. Cells were then incubated with monoclonal antibodies against $\alpha 2$, $\alpha 3, \alpha 6, \beta 1$, and $\beta 4$, integrins diluted in TBS (10 $\mu \mathrm{g} / \mathrm{ml})$ for 30 minutes on ice, carefully washed, and centrifuged. Cells were incubated with a fluorescein isothiocyanate-labeled goat-anti mouse secondary antibody diluted in TBS (1:30) for 30 minutes on ice, and analyzed on a FACScan flow cytometer (Beckman Coulter, Fullerton, California). As a negative control, cells were incubated with an antibody directed against human thyroglobulin (T $\gamma$ ) or $\alpha_{1 \mathrm{lb} \beta} 3$ (CP3) followed by a secondary antibody.

\section{Adhesion Assay}

Ninety-six-well plates (Sarstedt, Newton, North Carolina) were coated with either Ln-5 (1 $\mu \mathrm{g} / \mathrm{ml}), \mathrm{Ln}-1$ (10 $\mu \mathrm{g} / \mathrm{ml})$, or Coll IV $(10 \mu \mathrm{g} / \mathrm{ml})$ for 2 hours at $37^{\circ} \mathrm{C}$. As a negative control, wells were coated with blocking solution only. After extensive washing with PBS, plates were blocked with 10\% BSA in PBS for 2 hours at room temperature and washed with PBS. In some experiments, cells were plated in the presence of serum-free medium containing $30 \mu \mathrm{g} / \mathrm{ml}$ of functional $\alpha 2, \alpha 3, \alpha 6$, or $\beta 1$ anti-integrin antibodies. Cells were resuspended in a serum-free medium and seeded (80 $\times 10^{4}$ ) in each well. Plates were incubated for 30 minutes at $37^{\circ} \mathrm{C}$ in a humidified incubator containing $5 \% \mathrm{CO}_{2}$. After removing nonadherent cells by washing with PBS, cells were fixed with $100 \%$ methanol, stained with crystal violet, solubilized with $1 \%$ SDS and quantified with an ELISA plate reader, at $540 \mathrm{~nm}$.

\section{Transwell Haptotactic Migration Assay}

Transwell filters (8.0 $\mu \mathrm{m}$ pore size; Corning, New York) were coated on the bottom side with $\mathrm{Ln}-5(1 \mu \mathrm{g} / \mathrm{ml})$, Ln-1 (10 $\mu \mathrm{g} / \mathrm{ml})$, or Coll IV (10 $\mu \mathrm{g} / \mathrm{ml})$ diluted in PBS for 2 hours at room temperature. Filters were then washed twice with PBS containing $0.2 \%$ Tween 20 (PBST), blocked with blotto (5\% nonfat dry milk in PBST), and washed extensively with PBST and distilled water. As a control, filters were coated with blotto alone. After trypsinization, cells were collected and plated $\left(6 \times 10^{5}\right)$ in the upper part of the chamber, under serum-free conditions. In some experiments MIG1, TR1, and CM6 (30 $\mu \mathrm{g} / \mathrm{ml})$ monoclonal antibodies against Ln-5 were added to the migration medium. In other experiments, cells migrated in the presence of the MMP inhibitor BB-94 (concentrations ranging from 1 to $3 \mu \mathrm{g} / \mathrm{ml}$ ) in DMSO, or in DMSO alone. Exogenous human recombinant MMP-2 was activated (Itoh et al, 1995) and added to the medium in the migration assays with Hep3B, Alexander, HepG2, and HepG2.2.15. MCF-10 cells were used in this experiment as a control. Filters were incubated for 16 hours at $37^{\circ} \mathrm{C}$ in a humidified incubator containing $5 \% \mathrm{CO}_{2}$, fixed, and stained with $0.5 \%$ crystal violet in methanol. The nonmigratory cells were removed with a cotton tip and the migratory cells counted with a light microscope, at a magnification of $\times 400$. Each experiment was run in duplicate and four microscopic fields from each of the two filters were counted in every case. Results were expressed as the mean number of cells counted in each field, \pm standard deviation (Giannelli et al, 1997).

\section{Cell Scattering Assay}

Fifteen-thousand cells of each HCC cell line were maintained in culture for 24 hours in 24-well plates in DMEM or RPMI, plus $10 \%$ FCS. The medium was discarded and the cells were gently washed with sterile PBS. Cells were incubated overnight in serumfree medium in the presence or absence of purified Ln-5 (1 $\mu \mathrm{g} / \mathrm{ml})$. In the same experiments, $30 \mu \mathrm{g} / \mathrm{ml}$ of anti- $\alpha 2, \alpha 3, \alpha 6$, or $\beta 1$ integrin monoclonal blocking antibodies were added to the conditioned medium (an IgG monoclonal antibody was used as a control). After incubation, cells were washed, fixed with 3\% paraformaldehyde in PBS, and photographed with contrast phase optics using a Nikon Eclipse inverted microscope. Conditioned media were collected, concentrated, and analyzed by gelatin zymography (see "Gelatin Zymography and Immunoblotting"). 


\section{Chemoinvasion through a Reconstituted Basement Membrane}

The BM Matrigel matrix, extracted from the Engelbreth-Holm-Swarm mouse tumor, consists mainly of Ln-1, Coll IV, entactin, and Perlecan (Kleinman et al, 1982). At room temperature, the Matrigel matrix polymerizes into a reconstituted threedimensional BM with a similar structure and function to that of the BM in vivo (Kleinman et al, 1982). Eight-micron pore size polycarbonate filters (Nucleopore, Newton, Massachusetts) were coated with reconstituted BM reduced growth factor Matrigel (8 $\mu \mathrm{g} / \mathrm{cm}^{2}$ ) according to the manufacturer's instructions (Albini et al, 1987). The homogeneity of the coating was checked by protein staining. Filters were reconstituted with serum-free medium and placed in Boyden chambers. Cells $\left(3 \times 10^{6}\right)$ were resuspended in serum-free medium and plated in the upper part of the chamber. In the lower compartment, NIH3T3conditioned serum-free medium was used as a chemoattractant and nonconditioned serum-free medium was used as a negative control. In some experiments, BB-94 (3 $\mu \mathrm{g} / \mathrm{ml})$ in DMSO was added to the medium during migration, and DMSO alone was used as a control. Anti- $\alpha 2, \alpha 3, \alpha 6$, and $\beta 1$ integrin monoclonal blocking antibodies ( $30 \mu \mathrm{g} / \mathrm{ml})$ were added to the cells during invasion assays. Boyden chambers were incubated for 6 hours at $37^{\circ} \mathrm{C}$ in a humidified incubator with $5 \% \mathrm{CO}_{2}$ (Albini et al, 1987). Filters were fixed and stained, and noninvasive cells were removed with a cotton tip, as described above. The total number of invasive cells was quantified with image-analysis software. For each condition, three filters were run in each experiment. Results show the mean number of counted cells \pm standard deviation, each bar represents a different experiment. HT1080 cells were used as a positive control.

\section{Gelatin Zymography and Immunoblotting}

Confluent cells were incubated in plastic dishes for 48 hours under serum-free conditions. Conditioned media were concentrated with $80 \%$ ammonium sulfate, precipitated overnight, and centrifuged at 18,000 rpm. Pellets were then resuspended, dialyzed in appropriate buffer, and the protein concentration was measured. Gelatin zymography was performed as previously described (Giannelli et al, 1996). Briefly, $10 \mu \mathrm{g}$ of protein were loaded into each lane and separated on an SDS-PAGE gel containing $0.5 \%$ gelatin. Gels were washed twice for 30 minutes in $2.5 \%$ Triton and incubated in TRIS-saline buffer $(50 \mathrm{~mm}$ Tris- $\mathrm{HCl} \mathrm{pH}$ 7.4, containing $0.2 \mathrm{M} \mathrm{NaCl}, 5 \mathrm{mM} \mathrm{CaCl}_{2}$ ) at $37^{\circ} \mathrm{C}$ for 16 hours. Gels were stained with $0.2 \%$ Coomassie Blue in $50 \%$ methanol and $10 \%$ glacial acetic acid, then destained. MMP-9 and MMP-2 activity appeared as unstained areas. HT1080-conditioned medium was used as a positive control. For further investigation of HCC proteolytic activity, cell membrane fractions were prepared and analyzed for the presence of gelatinase bound on the cell membrane surface. Briefly, cells were washed, scraped from confluent dishes, and homogenized in $250 \mathrm{~mm}$ sucrose, $\mathrm{pH}$ 7.5. Nuclei were removed with low-speed centrifugation, and membrane fractions were recovered in the pellet after high-speed centrifugation. Membrane fraction samples were analyzed for protein concentrations, $30 \mu \mathrm{g}$ of the sample were loaded into each lane and analyzed by zymography.

TIMP-2 and MMP-2 were studied in the same conditioned media preparations as those used to examine the gelatinase activity. Twenty-five micrograms of each sample were separated by SDS-PAGE, transferred to polyvinylidene difluoride membranes (Millipore, Bedford, Massachusetts) and probed with a monoclonal antibody against human TIMP-2 (Miyazaki et al, 1993a) or human MMP-2. The presence of MT1-MMP was examined in cell membrane fractions prepared as described above. Forty micrograms of each sample were separated by SDS-PAGE, and processed for Western blotting. Membranes were probed with a polyclonal antibody directed against human MT1-MMP. In zymogram and Western blot experiments, the HT1080 cell line was used as a positive control. The protein concentration was measured by the bicinchoninic acid method (Pierce Chemical Company, Rockford, Illinois).

\section{Indirect Alkaline Phosphatase Immunoreactivity}

Surgical biopsies from 10 patients with HCC and 5 subjects undergoing surgery for trauma were snapfrozen in liquid nitrogen, mounted on Optimal Cutting Temperature 4583 embedding compound (Miles Laboratories Inc., Naperville, Illinois) and stored at $-80^{\circ} \mathrm{C}$. Five-micrometer-thick serial frozen sections were cut with a microtome (Microtom, HM 505E; Carl Zeiss, Oberkochen, Germany), transferred onto glass slides (Sigma Chemical Company) and processed for indirect alkaline phosphatase.

Briefly, sections were fixed in a chloroform/acetone mixture for 10 minutes at $4^{\circ} \mathrm{C}$, air dried, and incubated with $10 \mu \mathrm{g} / \mathrm{ml}$ of primary antibody diluted in RPMI medium containing 10\% FCS. After washing, sections were incubated with secondary antibody, washed, and incubated with a rabbit anti-mouse alkaline phosphatase-conjugated antibody. Reactions were developed with red fucsin, sections were counterstained with Mayer's hemalun solution, mounted with glycerol, and examined with a Nikon Eclipse photomicroscope (Nikon Company, Tokyo, Japan).

\section{Acknowledgements}

We thank L. Lupo (University of Bari Medical School, Bari, Italy) for providing the liver tissues. We also thank all of the investigators who generously provided us with reagents.

\section{References}

Albini A, Iwamoto Y, Kleinman HK, Martin GR, Aaronson SA, Kozlowski JM, and McEwan RN (1987). A rapid in vitro assay for quantitating the invasive potential of tumor cells. Cancer Res 47:3239-3245. 
Baker SE, Hopkinson SB, Fitchmun M, Andreason GL, Frasier F, Plopper G, Quaranta V, and Jones JC (1996). Laminin-5 and hemidesmosomes: Role of the alpha 3 chain subunit in hemidesmosome stability and assembly. J Cell Sci 109(Pt 10):2509-2520.

Band V and Sager R (1989). Distinctive traits of normal and tumor-derived human mammary epithelial cells expressed in a medium that supports long-term growth of both cell types. Proc Natl Acad Sci USA 86:1249-1253.

Bartolazzi A, Kaczmarek J, Nicolo G, Risso AM, Tarone G, Rossino P, Defilippi P, and Castellani P (1993). Localization of the alpha 3 beta 1 integrin in some common epithelial tumors of the ovary and in normal equivalents. Anticancer Res 13:1-11.

Bianchi FB, Biagini G, Ballardini G, Cenacchi G, Faccani A, Pisi E, Laschi R, Liotta L, and Garbisa S (1984). Basement membrane production by hepatocytes in chronic liver disease. Hepatology 4:1167-1172.

Bottini C, Miotti S, Fiorucci S, Facheris P, Menard S, and Colnaghi MI (1993). Polarization of the alpha 6 beta 4 integrin in ovarian carcinomas. Int J Cancer 54:261-267.

Bruix J, Barrera JM, Calvet X, Ercilla G, Costa J, SanchezTapias JM, Ventura M, Vall M, Bruguera M, and Bru C (1989). Prevalence of antibodies to hepatitis $C$ virus in Spanish patients with hepatocellular carcinoma and hepatic cirrhosis. Lancet 2:1004-1006.

Burgeson RE, Chiquet M, Deutzmann R, Ekblom P, Engel J, Kleinman $H$, Martin GR, Meneguzzi G, Paulsson M, and Sanes J (1994). A new nomenclature for the laminins. Matrix Biol 14:209-211.

Calvet X, Bruix J, Bru C, Gines P, Vilana R, Sole M, Ayuso MC, Bruguera M, and Rodes J (1990). Natural history of hepatocellular carcinoma in Spain. Five year's experience in 249 cases. J Hepatol 10:311-317.

Chen WT (1992). Membrane proteases: Roles in tissue remodeling and tumour invasion. Curr Opin Cell Biol 4:802809.

Chintala SK, Sawaya R, Gokaslan ZL, and Rao JS (1996). Modulation of matrix metalloprotease-2 and invasion in human glioma cells by alpha 3 beta 1 integrin. Cancer Lett 103:201-208.

Colombo M, Kuo G, Choo QL, Donato MF, Del Ninno E, Tommasini MA, Dioguardi N, and Houghton M (1989). Prevalence of antibodies to hepatitis $C$ virus in Italian patients with hepatocellular carcinoma. Lancet 2:1006-1008.

Coussens LM and Werb Z (1996). Matrix metalloproteinases and the development of cancer. Chem Biol 3:895-904.

Deryugina El, Bourdon MA, Reisfeld RA, and Strongin A (1998). Remodeling of collagen matrix by human tumor cells requires activation and cell surface association of matrix metalloproteinase-2. Cancer Res 58:3743-3750.

DiPersio CM, Shao M, Di Costanzo L, Kreidberg JA, and Hynes RO (2000). Mouse keratinocytes immortalized with large $\mathrm{T}$ antigen acquire alpha3beta1 integrin-dependent secretion of MMP-9/gelatinase B. J Cell Sci 113(Pt 16):29092921.

Fridman R, Bird RE, Hoyhtya M, Oelkuct M, Komarek D, Liang CM, Berman ML, Liotta LA, Stetler-Stevenson WG, and Fuerst TR (1993). Expression of human recombinant $72 \mathrm{kDa}$ gelatinase and tissue inhibitor of metalloproteinase-2 (TIMP-
2): Characterization of complex and free enzyme. Biochem $J$ 289(Pt 2):411-416.

Fukushima Y, Ohnishi T, Arita N, Hayakawa T, and Sekiguchi K (1998). Integrin alpha3beta1-mediated interaction with laminin-5 stimulates adhesion, migration and invasion of malignant glioma cells. Int $\mathrm{J}$ Cancer 76:63-72.

Giannelli G, Brassard J, Foti C, Stetler-Stevenson WG, Falk-Marzillier J, Zambonin-Zallone A, Schiraldi O, and Quaranta V (1996). Altered expression of basement membrane proteins and their integrin receptors in lichen planus: Possible pathogenetic role of gelatinases A and B. Lab Invest 74:1091-1104.

Giannelli G, Falk-Marzillier J, Schiraldi O, Stetler-Stevenson WG, and Quaranta V (1997). Induction of cell migration by matrix metalloprotease-2 cleavage of laminin-5. Science 277:225-228.

Giannelli G, Pozzi A, Stetler-Stevenson WG, Gardner HA, and Quaranta V (1999). Expression of matrix metalloprotease-2cleaved laminin-5 in breast remodeling stimulated by sex steroids. Am J Pathol 154:1193-1201.

Giannelli G, Savoia P, Schiraldi O, Lospalluti M, De Luca M, Marchisio PC, and Quaranta V (1994). Psoriatic lesions in patients with chronic liver disease are distinct from psoriasis vulgaris lesions, as judged on basis of integrin adhesion receptors. Hepatology 20:56-65.

Howard EW, Bullen EC, and Banda MJ (1991). Preferential inhibition of 72- and 92-kDa gelatinases by tissue inhibitor of metalloproteinases-2. J Biol Chem 266:13070-13075.

Hynes RO (1987). Integrins: A family of cell surface receptors. Cell 48:549-554.

Itoh Y, Binner S, and Nagase H (1995). Steps involved in activation of the complex of pro-matrix metalloproteinase 2 (progelatinase $A$ ) and tissue inhibitor of metalloproteinases (TIMP)-2 by 4 -aminophenylmercuric acetate. Biochem J 308(Pt 2):645-651.

Kajiji S, Tamura RN, and Quaranta V (1989). A novel integrin (alpha E beta 4) from human epithelial cells suggests a fourth family of integrin adhesion receptors. EMBO J 8:673-680.

Kleinman HK, McGarvey ML, Liotta LA, Robey PG, Tryggvason K, and Martin GR (1982). Isolation and characterization of type IV procollagen, laminin, and heparan sulfate proteoglycan from the EHS sarcoma. Biochemistry 21:6188-6193.

Kohn EC and Liotta LA (1995). Molecular insights into cancer invasion: Strategies for prevention and intervention. Cancer Res 55:1856-1862.

Koshikawa N, Giannelli G, Cirulli V, Miyazaki K, and Quaranta $\mathrm{V}$ (2000). Role of cell surface metalloprotease MT1-MMP in epithelial cell migration over laminin-5. J Cell Biol 148:615624.

Koshikawa N, Moriyama K, Takamura H, Mizushima H, Nagashima Y, Yanoma S, and Miyazaki K (1999). Overexpression of laminin gamma2 chain monomer in invading gastric carcinoma cells. Cancer Res 59:5596-5601.

Kreidberg JA (2000). Functions of alpha3beta1 integrin. Curr Opin Cell Biol 12:548-553.

Kubota S, Ito H, Ishibashi Y, and Seyama Y (1997). Antialpha3 integrin antibody induces the activated form of matrix metalloprotease-2 (MMP-2) with concomitant stimulation of invasion through matrigel by human rhabdomyosarcoma cells. Int J Cancer 70:106-111. 
Lora JM, Rowader KE, Soares L, Giancotti F, and Zaret KS (1998). Alpha3beta1-integrin as a critical mediator of the hepatic differentiation response to the extracellular matrix. Hepatology 28:1095-1104.

Melchiori A, Mortarini R, Carlone S, Marchisio PC, Anichini A, Noonan DM, and Albini A (1995). The alpha 3 beta 1 integrin is involved in melanoma cell migration and invasion. Exp Cell Res 219:233-242.

Meneguzzi G, Marinkovich MP, Aberdam D, Pisani A, Burgeson R, and Ortonne JP (1992). Kalinin is abnormally expressed in epithelial basement membranes of Herlitz's junctional epidermolysis bullosa patients. Exp Dermatol 1:221229.

Miyazaki K, Funahashi K, Numata Y, Koshikawa N, Akaogi K, Kikkawa Y, Yasumitsu H, and Umeda M (1993a). Purification and characterization of a two-chain form of tissue inhibitor of metalloproteinases (TIMP) type 2 and a low molecular weight TIMP-like protein. J Biol Chem 268:14387-14393.

Miyazaki K, Kikkawa $Y$, Nakamura A, Yasumitsu $H$, and Umeda M (1993b). A large cell-adhesive scatter factor secreted by human gastric carcinoma cells. Proc Natl Acad Sci U S A 90:11767-11771.

Mizushima H, Miyagi Y, Kikkawa Y, Yamanaka N, Yasumitsu H, Misugi K, and Miyazaki K (1996). Differential expression of laminin-5/ladsin subunits in human tissues and cancer cell lines and their induction by tumor promoter and growth factors. J Biochem (Tokyo) 120:1196-1202.

Morini M, Mottolese M, Ferrari N, Ghiorzo F, Buglioni S, Mortarini R, Noonan DM, Natali PG, and Albini A (2000). The alpha 3 beta 1 integrin is associated with mammary carcinoma cell metastasis, invasion, and gelatinase B (MMP-9) activity. Int J Cancer 87:336-342.

Murphy G and Gavrilovic J (1999). Proteolysis and cell migration: Creating a path? Curr Opin Cell Biol 11:614-621.

Nagase H (1997). Activation mechanisms of matrix metalloproteinases. Biol Chem 378:151-160.

Nejjari M, Hafdi Z, Dumortier J, Bringuier AF, Feldmann G, and Scoazec JY (1999). alpha6beta1 integrin expression in hepatocarcinoma cells: Regulation and role in cell adhesion and migration. Int $\mathrm{J}$ Cancer 83:518-525.

Pellegrini R, Bazzini P, Tosi E, Tagliabue E, Conforti G, Dejana E, Menard S, and Colnaghi MI (1992). Production and characterization of two monoclonal antibodies directed against the integrin beta 1 chain. Tumori 78:1-4.

Plopper G, Falk-Marzillier J, Glaser S, Fitchmun M, Giannelli G, Romano T, Jones JC, and Quaranta V (1996). Changes in expression of monoclonal antibody epitopes on laminin- $5 r$ induced by cell contact. J Cell Sci 109(Pt 7):1965-1973.
Pyke C, Salo S, Ralfkiaer E, Romer J, Dano K, and Tryggvason K (1995). Laminin-5 is a marker of invading cancer cells in some human carcinomas and is coexpressed with the receptor for urokinase plasminogen activator in budding cancer cells in colon adenocarcinomas. Cancer Res 55: 4132-4139.

Raney AK, Milich DR, Easton AJ, and McLachlan A (1990). Differentiation-specific transcriptional regulation of the hepatitis $B$ virus large surface antigen gene in human hepatoma cell lines. J Virol 64:2360-2368.

Roskelley CD, Srebrow A, and Bissell MJ (1995). A hierarchy of ECM-mediated signalling regulates tissue-specific gene expression. Curr Opin Cell Biol 7:736-747.

Ruoslahti E (1991). Integrins J Clin Invest 87:1-5.

Ruoslahti E and Giancotti FG (1989). Integrins and tumor cell dissemination. Cancer Cells 1:119-126.

Scoazec JY, Flejou JF, D’Errico A, Fiorentino M, Zamparelli A, Bringuier AF, Feldmann G, and Grigioni WF (1996). Fibrolamellar carcinoma of the liver: Composition of the extracellular matrix and expression of cell-matrix and cell-cell adhesion molecules. Hepatology 24:1128-1136.

Shaw LM, Rabinovitz I, Wang HH, Toker A, and Mercurio AM (1997). Activation of phosphoinositide 3-OH kinase by the alpha6beta4 integrin promotes carcinoma invasion. Cell 91: 949-960.

Stetler-Stevenson WG, Aznavoorian S, and Liotta LA (1993). Tumor cell interactions with the extracellular matrix during invasion and metastasis. Annu Rev Cell Biol 9:541-573.

Sugiura T and Berditchevski $F$ (1999). Function of alpha3beta1-tetraspanin protein complexes in tumor cell invasion. Evidence for the role of the complexes in production of matrix metalloproteinase 2 (MMP-2). J Cell Biol 146:1375-1389.

Vailly J, Verrando P, Champliaud MF, Gerecke D, Wagman DW, Baudoin C, Aberdam D, Burgeson R, Bauer E, and Ortonne JP (1994). The 100-kDa chain of nicein/kalinin is a laminin B2 chain variant. Eur J Biochem 219:209-218.

Yamanaka N, Okamoto E, Toyosaka A, Mitunobu M, Fujihara $\mathrm{S}$, Kato T, Fujimoto J, Oriyama T, Furukawa $\mathrm{K}$, and Kawamura E (1990). Prognostic factors after hepatectomy for hepatocellular carcinomas. A univariate and multivariate analysis. Cancer 65:1104-1110. 